
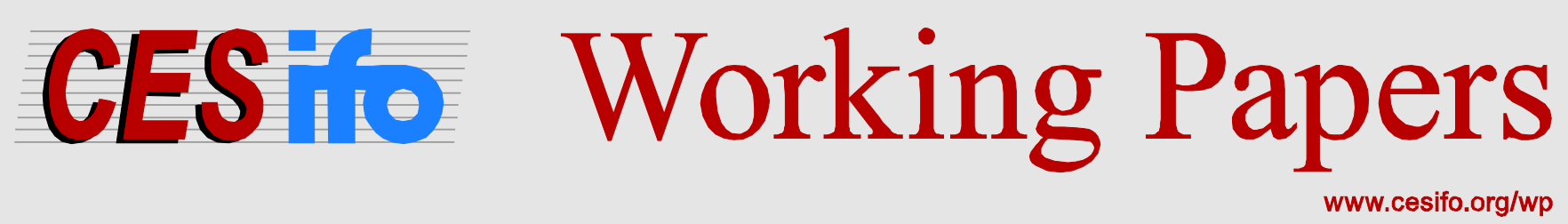

\title{
The Political Economy of Pricing Car Access to Downtown Commercial Districts
}

\author{
Bruno De Borger \\ Antonio Russo
}

CESIFO WORKING PAPER NO. 5294

CATEGORY 1: PuBlic FinANCE

ORIGINAL VERSION: APRIL 2015

THIS VERSION: JUNE 2016
An electronic version of the paper may be downloaded
- from the SSRN website:
- from the RePEc website:
WwW.SSRN.com
www.RePEc.org
- from the CESifo website:
www.CESifo-group.org/wp




\title{
The Political Economy of Pricing Car Access to Downtown Commercial Districts
}

\begin{abstract}
We study the political economy of pricing access to downtown commercial districts, using parking fees as the main example. A spatial equilibrium model is embedded in a political economy framework in which special interest groups (urban and suburban retailers, local residents) lobby the city government. We have the following results. If downtown and suburban stores sell a homogeneous good, the local government underprices downtown parking if suburban stores sell at small enough margins compared to traditional downtown retailers. If goods are heterogeneous and some consumers engage in multiple-stop shopping (i.e., shop both downtown and in the suburbs), suburban stores will not lobby at all; lobbying by downtown retailers leads to parking fees below the social optimum. Furthermore, local residents do not necessarily lobby for high parking fees on downtown shoppers. If a decline in urban stores leads to negative externalities (urban blight) they may join forces with downtown retailers and lobby against high parking fees on shoppers.
\end{abstract}

JEL-Code: D430, D720, H230, R410.

Keywords: parking fees, lobbying, retailers, multiple-stop shopping.

\author{
Bruno De Borger \\ Department of Economics \\ University of Antwerp \\ Prinsstraat 13 \\ Belgium - 2000 Antwerp \\ bruno.deborger@uantwerpen.be
}

\author{
Antonio Russo \\ KOF Swiss Economic Institute \\ ETH Zurich \\ Leonhardstrasse 21 \\ Switzerland - 8092 Zurich \\ russo@kof.ethz.ch
}

We thank Brian Adams, Richard Arnott, Philippe De Donder, Umberto Galmarini, Eren Inci and participants to seminars at ETH Zurich, Toulouse School of Economics, IEB Barcelona, the University of Antwerp, VU-Amsterdam, the 2014 ITEA and LAGV conferences and the Urban Economics Association meetings in Atlanta and St. Petersburg for useful comments and suggestions. All errors are ours. 


\section{Introduction}

Car travel to downtown urban areas imposes significant costs on society, many of which car users ignore. These costs include the external costs of congestion, pollution, noise and accident risks; moreover, they also include the cost of unpriced or underpriced parking space ${ }^{1}$. Many economists have argued, therefore, that road transport is generally underpriced, and that the resulting welfare loss is considerable (see, for example, Small and Verhoef, 2007). ${ }^{2}$ This is particularly true in downtown commercial areas, where both the opportunity cost of land and the level of congestion are often very high (Arnott, 2011; Inci, 2015).

The purpose of this paper is to propose a positive theory of pricing access to downtown commercial districts that may help to explain why governments often set prices too low from a social perspective. Specifically, we develop a spatial equilibrium model to study the political economy of pricing car access when various special interest groups (different types of urban and suburban retailers, local residents) lobby the city government. For purposes of concreteness we use parking fees as our driving example, but the results also apply to other pricing measures controlling access to city centers, such as cordon tolls or area charges.

In many cities, the downtown commercial district is the primary focus of policies intended to regulate car use, and ample anecdotal evidence suggests that at least three special interest groups may lobby to affect local governments' pricing policies. First, both Shoup (2005) and Arnott (2011) argue that in US-cities downtown retailers, concerned by competition from suburban malls, exercise political pressure to express their demands. The same seems to happen in other countries. For example, retailers formed the Greater Manchester Momentum Group to lobby against cordon tolls in Manchester (ultimately abandoned in 2008). ${ }^{3}$ As another illustration, consider the following quote from a report by the Federation of Small Businesses, which represents a large share of British familyrun businesses, discussing parking policy in the British town of Harleston:

“In spring 2008 South Norfolk Council recommended that Harleston's town centre car parks should introduce charges. The Federation of Small Businesses threw its weight behind a local resident campaign to urge the district authority to rethink the introduction of charges... When the case was made for the crucial relationship between parking policy and a successful town centre, South Norfolk Council decided to rethink the introduction of car park charges” (FSB, 2008).

\footnotetext{
${ }^{1}$ It is estimated that land dedicated to parking in the United States covers an area that is roughly equal to the size of Massachusetts (Jackle and Sculle, 2004), at an estimated monthly cost of at least 125\$ per parking space (Shoup, 2005). ${ }^{2}$ Despite longstanding support by economists, some form of road pricing exists in only a handful of cities, e.g., London and Stockholm (Eliasson, 2009). In many cases, proposals for tolls have met retailers' opposition. Throughout the paper we stick to the parking interpretation for concreteness, but we briefly return to the road pricing interpretation in Section 6 below.

${ }^{3}$ See http://www.rochdaleonline.co.uk/Rochdale News_Business News _The Greater Manchester Momentum GroupRochdale Online.htm. Similar examples include Milan, San Francisco (Bent and Singa, 2009) and Montréal (http://ici.radio-canada.ca/regions/Montreal/2010/11/17/008-plateau-stationnement-commercants.shtml)
} 
Second, although downtown retailers might lose business due to higher parking fees, other politically influential stakeholders may benefit. For example, large stores located in the suburbs may attract part of the demand lost by downtown shops (note that they often provide free parking (Hasker and Inci, 2014)). ${ }^{4}$ These stores may organize themselves to lobby local policymakers, and they are often observed to do so. ${ }^{5}$ Third, downtown residents may favor parking fees for non-residents because they compete for limited parking space, and they may lobby to press their demands. ${ }^{6}$

The model developed below considers a linear city with a downtown commercial district, populated by traditional downtown retailers (e.g. delis, grocery stores or convenience stores) at one edge, and large suburban stores (e.g., hypermarkets) at the other. We assume shoppers travel by car; their trips downtown entail an external cost (e.g., noise, pollution, or the cost of parking space). Hence, the government should ideally regulate access to the downtown district via an appropriate pricing policy. This increases the relative cost of shopping downtown, possibly shifting consumer demand towards suburban stores. We embed this simple spatial competition model in a political economy framework à la Grossman and Helpman (1994), whereby both downtown and suburban retailers may lobby the local government.

We find that in equilibrium lobbying may result in equilibrium parking fees that are higher or lower than socially optimal. If downtown and suburban stores sell a homogeneous good, we show that the local government underprices downtown parking if suburban stores sell at small enough margins compared to traditional downtown retailers. If goods are heterogeneous and some consumers engage in multiple-stop shopping (i.e., shop both downtown and in the suburbs), we find that suburban stores will not lobby at all; lobbying by downtown retailers leads to parking fees below the social optimum. Furthermore, we find that local residents do not necessarily lobby for high parking fees on downtown shoppers. Whether they lobby in favor or against high parking fees depends on the degree to which a decline in urban stores leads to urban blight.

In the baseline scenario, we assume that retailers sell a homogeneous good and consumers visit either the downtown district or suburban stores. In most real-world cities (Foster et al., 2006, Basker, 2007), suburban stores are primarily large establishments that sell large quantities of goods

\footnotetext{
${ }^{4}$ Scholars and commentators mention accessibility by car as one of the key competitive advantages of suburban establishments. See, e.g., Lagakos (2009) and UK Dept. for Communities and Local Government (2013, p.7).

${ }^{5}$ Anecdotal evidence indicates that large suburban retailers (e.g., big grocery store chains) lobby local governments on several issues. Consider, for instance, land-use regulation. There are several reports of lobbying by supermarket chains to tighten planning rules in order to block entry of similar competitors. See, e.g. Friends of the Earth (2006).

${ }^{6}$ In several cities, central residents have encouraged the government to raise fees on non-resident drivers or provide residential parking permits (Inci, 2015). van Ommeren et al. (2011) report a large difference between parking fees applied to residents and to outside visitors in central Amsterdam. By contrast, in other (usually smaller) cities, residents have shown concerns about the loss of vitality of the area they live in. For instance, in the case of Harleston mentioned above, both retailers and local residents backed the campaign against parking fees.
} 
at relatively small margins. By contrast, the scale of downtown retailers is typically smaller, but they charge larger mark-ups. ${ }^{7}$ By capturing these features in a simple way, our model shows that the value of attracting (or retaining) a customer is, at the margin, smaller to the latter than to the former. Thus, one dollar "spent” lobbying to alter travel costs produces a greater impact on profits of downtown retailers (taken together) than on suburban stores. As a result, it is shown that, unless the mark-up charged by suburban stores is much larger than that of downtown shops, the government adopts lower-than-optimal downtown parking fees.

Next, we allow downtown retailers and suburban stores to sell differentiated goods. Furthermore, we assume consumers can visit both types of retailers, to enjoy the whole variety on the market. ${ }^{8}$ Intuitively, competition between downtown retailers and suburban stores is now weaker than in the previous scenario. Accordingly, we show that when some consumers visit both retail areas, the incentive of suburban stores to lobby for the downtown parking fee disappears. The reason is that the demand faced by suburban stores includes consumers that only shop in the suburbs and consumers that also shop downtown. A higher parking fee may induce some of them to stop shopping downtown, but has no effect on their choice to shop in the suburbs. As a result, only downtown retailers lobby, and the government consequently sets the fee below the optimal level. By a similar principle, we find that not all downtown retailers lobby against the fee. Specifically, only those whose demand consists in both single- and multiple-stop shoppers oppose it. In our model, these retailers sell goods that are more differentiated from the goods available at suburban stores.

Finally, we consider the preferences of residents within the downtown district, and allow for an endogenous number of downtown retailers. Residents may dislike car trips from outsiders, for instance because they compete with them for parking space. Nonetheless, if higher parking fees reduce the volume of non-resident shoppers, downtown retailers -- already exposed to competition from suburban stores -- may decide to abandon the downtown district. This reduces the welfare of local residents. We show that, if exit of downtown retailers is not too strong a concern, residents lobby for higher parking fees on visitors. Otherwise, downtown residents lobby, together with downtown retailers, against parking fees.

This paper relates to several strands of literature. It contributes to the growing literature on the political economy of urban transportation (see, e.g., Borck and Wrede, 2005 and 2008, Brueckner and Selod, 2006, De Borger and Proost, 2012, Russo, 2013). It has also linkages to the literature on

\footnotetext{
${ }^{7}$ According to data published by Sageworks, over the five years from 2007 to 2012, the average net profit margin for US supermarkets was below $2 \%$, less than half of the corresponding figure for specialty food stores (see Forbes.com, "Supermarkets face tough choices if food costs rise", retrieved June 2014). Statistics Canada reports that the net operating margin of food and beverage stores is $7 \%$, compared to $2 \%$ for supermarkets (see CCSA, 2012).

${ }^{8}$ The relevance of multiple-stop shopping has been emphasized in recent studies of competition among retailers. See, e.g., Chen and Rey (2012) and Uschev et al. (2015).
} 
lobbying to affect competition. For example, Aghion and Schankerman (2004) propose a model of spatial competition between asymmetric firms that lobby the government on infrastructure provision. They show that, under some conditions, inefficient firms may block welfare-enhancing investment to protect their market power. More recently, Baldwin and Robert-Nicoud (2007) show that firms that operate in declining sectors have stronger incentives to lobby. In a similar vein, Ghosh and Meagher (2014) study how market structure may affect voting on infrastructure provision. In our model, policy is not intended to enhance competition, but to internalize some external costs. Moreover, the extent to which firms are affected by government policy depends on their location.

Our model is also related to the literature on competition between firms in separated market places. Smith and Hay (2005) develop a model of one-stop shopping with two spatially separated marketplaces, assuming individual demand for variety is perfectly inelastic. More closely related in spirit is the recent paper by Uschev et al. (2015); they study competition between small urban retailers and large suburban shopping malls, allowing for multi-stop shopping. Whereas they focus on questions related to the desirability of government regulation, we concentrate on what type of regulation to expect, given the incentives of the different stakeholders involved. ${ }^{9}$

Finally, our analysis contributes to the recent literature on the economics of parking. A few studies focus on pricing of garage parking in the presence of free on-street parking (Calthrop and Proost, 2006; Inci and Lindsey, 2015). Various other papers emphasize the role of cruising for onstreet parking space in downtown areas (see, e.g., Glazer and Niskanen, 1992; Arnott and Inci, 2006; Arnott and Rowse, 1999, 2009; Arnott, Inci and Rowse, 2015; Anderson and de Palma, 2004). Some studies have also looked at different organizational structures to deal with downtown parking. For example, Shoup (2005) compares the establishment of pure residential parking areas with a parking policy that taxes outsiders while local residents park for free. More recently, van Ommeren et al. (2011) emphasize the inefficiencies that can result from such a differentiated parking policy. Finally, a few papers study the relation between parking and shopping. Hasker and Inci (2014) show that parking in suburban malls should be provided for free if consumers are risk averse, and provide a rationale for minimum parking requirements. Molenda and Sieg (2013) model the trade-off between privileged parking for residents and product variety offered in a vibrant city district. Hymel (2014) empirically studies the effect of on-street parking fees on retail sales in commercial districts.

The remainder of the paper is organized as follows. We present the baseline model in Section 2. The model is solved in Section 3. In Section 4, we allow for multiple-stop shopping. Section 5 contains further extensions. We provide some concluding remarks in Section 6.

\footnotetext{
${ }^{9}$ An additional difference is that we allow for some overlapping between the set of goods available downtown and in suburban stores. See also Brandao et al. (2014).
} 


\section{The Baseline Model}

Spatial structure. We consider a linear city of unit length. The population has unit size and is composed of identical individuals uniformly distributed on the unit line. We denote by $x$ the (exogenous) position of a consumer, with $x \sim U[0,1]$. The downtown commercial district (the city's "shopping street") is located in position 0, the city center. Many identical downtown retailers (e.g. delis, specialized food stores, restaurants...) are located there. We will sometimes refer to them as retailers of type A. At the edge of the city, in position 1, we have a large suburban store (e.g., a hypermarket or a superstore), denoted B. Furthermore, there are additional suburban stores, identical to B, at a distance $y$ from the city's edge. We denote their out-of-town location by $\mathrm{C}$.

A consumer located in position $x$ has to travel $x$ units of distance to shop downtown. If he/she decides to shop elsewhere, he/she has the option of either traveling $(1-x)$ miles to shop at the suburban store B, or $(1-x+y)$ to shop in C. We depict the spatial structure of the model in Figure 1.

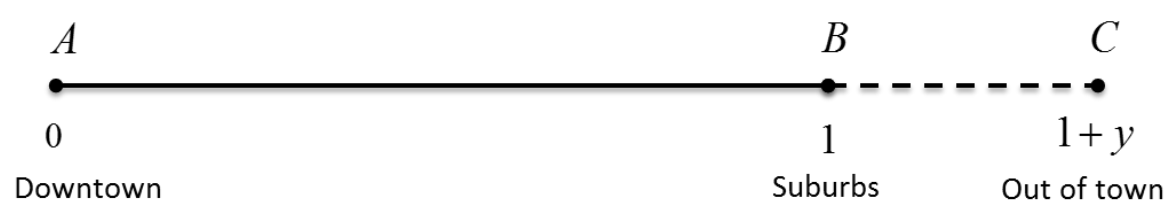

Figure 1: Spatial setup of the model

Retailers. There are two kinds of retailers: downtown (i.e., type-A) retailers and suburban stores. In the baseline model, we assume all retailers sell the same good. This assumption is relaxed in Section 4 below.

Downtown retailers are identical, price-taking firms. We normalize their number to one. ${ }^{10}$ Each of them has a decreasing returns technology, described by the quadratic cost function

$$
c_{A}\left(q_{A}\right)=\frac{q_{A}^{2}}{2},
$$

where $q_{A}$ is the quantity sold. Denoting the price charged by a downtown retailer by $p_{A}$ and using (1), we write its profit as

$$
\pi_{A}=p_{A} q_{A}-\frac{q_{A}^{2}}{2} .
$$

Note that quadratic costs greatly improve tractability but is not essential for our results. The assumption of decreasing returns may be justified in several ways: first, many downtown retailers are

\footnotetext{
${ }^{10}$ We assume the number of retailers is exogenous. This assumption is relaxed in Section 5 below.
} 
traditional, small ‘entrepreneurial’ shops: the owner's labor is typically a crucial input that gets scarcer as the business increases in size. Second, space is a significant constraint in downtown commercial districts, making expansion increasingly costly. Third, downtown retailers face increasing logistic costs (especially in comparison with suburban stores). For example, it is harder for them to make use of large trucks for deliveries.

Contrary to downtown retailers, suburban stores are typically large establishments that exploit economies of scale and scope and have low, virtually constant marginal costs (Foster et al., 2006, Basker, 2007). Moreover, they face little of the space constraints faced by downtown retailers. In order to capture this difference in a simple way, we assume that suburban stores are endowed with a constant-returns technology with - for simplicity -- zero marginal cost (fixed costs are ignored). This implies that, for any quantity, the marginal cost of traditional retailers is higher than that of suburban stores.

The profit of the suburban store B is

$$
\pi_{B}=p_{B} q_{B}
$$

where $p_{B}$ and $q_{B}$ denote, respectively, the price and quantity sold by B. We assume B is a pricesetting firm. This is justified by its large size and dominant position in the local market. ${ }^{11}$ To keep the analysis simple, we let the suburban stores in the out-of-town location C play a passive role. Specifically, we assume that stores in $C$ charge an exogenous price $p_{C}$, which we normalize to zero. ${ }^{12}$ As we illustrate below, their role in our model is to provide an alternative option for city consumers that do not intend to shop downtown, and their presence constrains store B's market power.

Individuals. We assume all individuals in the city consume one unit of a homogeneous retail good. Shopping implies some travel cost. All travel takes place by car (alternative modes, e.g. public transport, are considered in Section 6 below). A consumer located at position $x$, and buying at a downtown (i.e., type-A) retailer, obtains the following utility

$$
U(x, A)=V-p_{A}-\beta x-t .
$$

In this expression, $V$ is the gross utility of consuming the retail good, $\beta$ is the cost of travel (per unit of distance) and $t \geq 0$ is a user fee charged to individuals who travel by car to the downtown

\footnotetext{
${ }^{11}$ Because of its location, store B primarily serves consumers in the city, whereas the suburban stores in C serve consumers living outside (i.e., in $\mathrm{C}$ or further away from the city). We do not explicitly model these consumers. In principle, a store in $\mathrm{C}$ might also serve consumers within the city. However, given the extra travel cost $y$, B could always undercut it, serving all city consumers that do not shop downtown. As we show below, this is indeed what happens in equilibrium.

${ }^{12}$ As will become clear below, a positive $p_{C}$ does not change the analysis, because it has the same effect on consumer utility as the extra travel distance $y$. Alternatively, we could endogenize $p_{C}$. Given our setup, assuming stores in $C$ are not differentiated and compete à la Bertrand, $p_{C}=0$ would in fact be the equilibrium outcome.
} 
commercial district. For concreteness, we interpret this fee as a parking fee. However, one can also interpret $t$ as a cordon toll to access the city center. We discuss this alternative interpretation in the concluding section.

A consumer located in position $x$ and shopping at the suburban store $B$ obtains utility

$$
U(x, B)=V-p_{B}-\beta(1-x) .
$$

Finally, the consumer who shops at a suburban store outside the city obtains

$$
U(x, C)=V-\beta(1-x+y) .
$$

Comparing (5) and (6) it is clear that, conditional on shopping at a suburban store, a consumer in location $x$ will choose B if and only if $p_{B}$ falls short of the extra transport cost to shop in C (when indifferent, a consumer is assumed to always choose the closest outlet, i.e., B):

$$
U(x, B) \geq U(x, C) \Leftrightarrow p_{B} \leq \beta y .
$$

As will become clear shortly, no consumer in the city chooses $\mathrm{C}$ in equilibrium.

To compute demands, it is useful to identify the consumer who is indifferent between shopping downtown and shopping either in the suburbs or out of town. We denote her position by $\bar{x}$. As illustrated on Figure 2, all consumers positioned to its left shop downtown, whereas all those to its right shop either in store B or out of town.

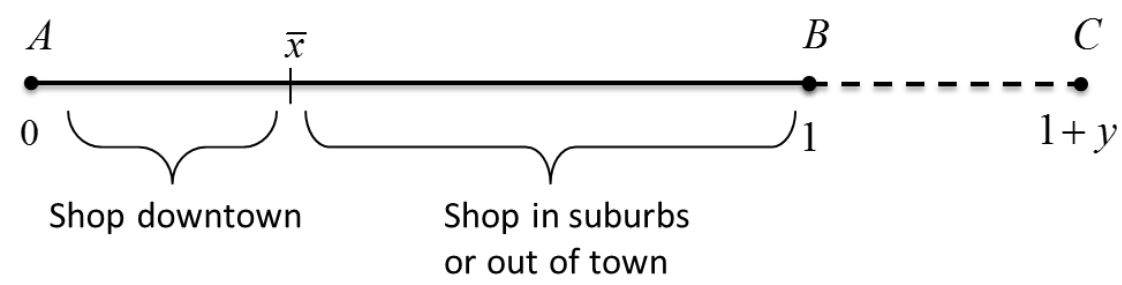

Figure 2: Consumer position and where to shop

Position $\bar{x}$ is defined by $U(\bar{x}, A)=\max (U(\bar{x}, B) ; U(\bar{x}, C))$. Using (4), (5) and (6), we find

$$
\bar{x}=\frac{\min \left[p_{B}, \beta y\right]-p_{A}+\beta-t}{2 \beta} .
$$

Denoting the demand for downtown retailers $\mathrm{A}$ and for stores $\mathrm{B}$ and $\mathrm{C}$ by $q_{\mathrm{A}}, . q_{\mathrm{B}}$. and $q_{\mathrm{C}}$, respectively, we then have:

$$
\begin{aligned}
& q_{A}=\bar{x}, \\
& q_{B}=1-\bar{x}=1-q_{A} \quad \text { and } \quad q_{C}=0 \quad \text { if } \quad \min \left(p_{B}, \beta y\right)=p_{B} \text {, } \\
& \text { or } \quad q_{C}=1-\bar{x}=1-q_{A} \text { and } q_{B}=0 \text { otherwise. }
\end{aligned}
$$


Welfare. Assuming that parking revenues are lump-sum redistributed to consumers, aggregate consumer surplus associated with shopping can be defined as:

$$
C S=\int_{0}^{\bar{x}} U(x ; A) d x+\int_{\bar{x}}^{1} U(x ; B) d x+t q_{A} .
$$

Using the definitions of utility in (4), (5) and (6), together with demand specifications (8) and (9), this can be rewritten, after straightforward algebra, as follows

$$
C S=V-\beta \frac{q_{A}^{2}}{2}-\beta\left(1-q_{A}\right)+\beta \frac{\left(1-q_{A}^{2}\right)}{2}-p_{A} q_{A}-\min \left[p_{B}, \beta y\right] \cdot\left(1-q_{A}\right) \text {. }
$$

Each car trip to the downtown commercial district entails an external cost $e$. This cost is external in the sense that consumers disregard it when making travel decisions. Several interpretations may be given to $e$. To begin, it can be interpreted as the cost society sustains in order to provide a parking space. This includes both the physical and the opportunity cost of the resources allocated to parking (e.g., land). Furthermore, $e$ might capture other externalities typically associated to car travel, e.g., noise and pollution. Although external costs may also be associated to car trips to the suburbs, it seems fair to say that they are probably less relevant than downtown: for example, the opportunity cost of land is larger than in the suburbs. Furthermore, population density is higher in proximity to downtown districts. Hence, the external cost of pollution and noise is likely to be more relevant than for trips to the suburbs. Because what matters for our results are cost differences, we disregard the external costs of car trips to the suburbs. Finally, observe that by assuming that $e$ is constant, we ignore congestion, but we only do so for simplicity. Adding it would only complicate the analysis without changing the qualitative results. We return to this issue the concluding section.

Adding consumer surplus, profits and subtracting external costs, we obtain social welfare:

$$
S W=C S+\sum_{i=A, B, C} \pi_{i}-e q_{A} .
$$

Using (2), (3) and (10), expression (11) can be rewritten, after straightforward simplifications, as:

$$
S W=V-\beta \frac{q_{A}^{2}}{2}-\beta\left(1-q_{A}\right)+\beta \frac{\left(1-q_{A}^{2}\right)}{2}-\frac{q_{A}^{2}}{2}-e q_{A}-\left(1-q_{A}\right) \beta y I_{P_{B}>\beta y} .
$$

In this expression, $I_{P_{B}>\beta y}$ is an indicator function taking value one if and only if $p_{B}>\beta y$ (which is necessary and sufficient for consumers who do not shop downtown to choose $\mathrm{C}$ rather than $\mathrm{B}$ ).

Government and lobbying. The city government controls the parking fee $t$. Our model of the political decision process follows the standard "Protection for Sale" framework (Grossman and Helpman, 1994; Grossman et al., 1997). We do not explicitly model elections, but assume that politicians in office are subject to the influence of organized pressure groups. This comes in the form 
of promises to reward decision-makers for adopting policies that benefit group members. Examples are contributions to electoral campaigns, in the form of monetary or in-kind transfers (e.g. logistic or administrative support). Alternatively, lobbies can make indirect contributions by helping the incumbent administration finance local public goods or services. In the extreme, one can think of contributions as outright bribes. Politicians in office value these contributions either because they can pocket them or because they increase the probability of being re-elected.

The probability of remaining in office may also depend on social welfare. Therefore, we assume that the objective of the government is to maximize a weighted sum of social welfare (12) and lobbying contributions $L_{i}$ (to be described in more detail below):

$$
W_{G}=\eta S W+(1-\eta) \sum_{i=A, B} L_{i} .
$$

In expression (13), $\eta$ represents the degree of government "benevolence": the larger it is, the more the government cares for social welfare and the less it values contributions by lobbies. In the baseline model only downtown retailers A and the suburban store B lobby the city government. ${ }^{13}$ Obviously, in order to lobby it is necessary to form a lobbying outfit. In practice, doing so requires costly preliminary steps like opening offices and hiring support staff, lawyers and lobbyists, etc. In line with most of the literature, however, we ignore these costs and let lobbies exogenously exist. We also assume, for simplicity, that the government accepts contributions from all lobbies (though these may be zero in equilibrium).

Consider the way in which contributions to the government are made. It is natural to expect a lobby's support to politicians to be conditional on the policy chosen. In our framework, $L_{i}$ are contribution schedules that lobbies commit to before the government chooses $t$. Bernheim and Whinston (1986) have shown that if contribution schedules are differentiable (we assume this is the case), in equilibrium they are locally 'truthful', in the sense that the contribution and the lobby's objective function vary with $t$ in the same way. Formally, provided that the contribution offered by lobby $i$ is positive, we have

$$
\frac{\partial L_{i}(t)}{\partial t}=\frac{\partial \pi_{i}(t)}{\partial t}, i=A, B
$$

Moreover, the contribution offered in equilibrium has the standard form

$$
L_{i}(t)=\max \left[\pi_{i}(t)-\phi_{i}, 0\right], i=A, B .
$$

where $\phi_{i}>0$ is constant (i.e., it does not depend on $t$ ). The formal proof of these statements is

\footnotetext{
${ }^{13}$ We ignore lobbying by suburban stores in C as they primarily target consumers living elsewhere: the parking fee in the city center has a negligible impact on their profit. In fact, as will be shown below, in equilibrium the demand they face is independent of $t$.
} 
standard (see Appendix 1).

Timing and definition of equilibrium. The timing of events is as follows:

1. Policy formation. Lobbies $i=A, B$ commit simultaneously to a contribution schedule $L_{i}$; the government then decides on $t$.

2. Utility and profit maximization. Given $t$, firms and consumers make profit and utility maximizing decisions: (i) Suburban store B decides on $p_{B}$, (ii) downtown retailers decide on $q_{A}$ and (iii) consumers choose where to shop.

We focus on (pure-strategy) Subgame-Perfect Nash Equilibria. An equilibrium is a vector of contribution schedules $\left\{L_{i}^{e}\right\}_{i=A, B}$, a parking fee $t^{e}$ and a vector of prices $\left\{p_{i}\right\}_{i=A, B}$ and quantities $\left\{q_{i}\right\}_{i=A, B, C}$ such that: (i) $t^{e}$ maximizes $W_{G}$ given $\left\{L_{i}^{e}\right\}_{i=A, B}$, (ii) $L_{i}^{e}$ maximizes $\pi_{i}\left(t^{e}\right)-L_{i}^{e}\left(t^{e}\right)$ for $i=A, B$, and (iii) $\left\{p_{i}\right\}_{i=A, B}$ and $\left\{q_{i}\right\}_{i=A, B, C}$ are the outcome of stage 2, given $t^{e} \cdot{ }^{14}$

Before turning to the solution of the model, two remarks on its interpretation. First, the retail good can also be thought of as a basket of different goods purchased in fixed proportions. Assume that each downtown retailer sells one such good (still as a price taker, as there is a large number of downtown retailers per each good), whereas suburban stores sell instead the entire basket. If consumers are one-stop shoppers (i.e., only shop in one of the retail areas, for example because they are highly time-constrained), the analysis is essentially unchanged. Nevertheless, for simplicity, our baseline model focuses on a single undifferentiated good; Section 4 below considers the case where downtown retailers and suburban stores do not sell the same goods and consumers may visit both retail areas. Second, although we interpret $x$ and $y$ as travel costs, it is possible -- as in standard models of product differentiation -- to interpret these parameters as capturing heterogeneous preferences for firms and/or heterogeneous product (or service) quality. In this vein, one could also interpret $x$ as a consumer's intensity of preferences for downtown retailers versus suburban stores, and $y$ as the quality advantage of suburban store B compared to the other stores in C.

\section{Solving the model}

We solve the model by backward induction. We first analyze the decisions of firms and

\footnotetext{
${ }^{14}$ As customary (see, e.g., Grossman and Helpman, 1994), it can be shown that the equilibrium values of $\phi_{i}$ are such that lobby $i$ 's contribution is just high enough to make the government indifferent between adopting $t^{e}$ and adopting a fee that maximizes $W_{G}$ if $i$ 's contribution is zero (and keeping equilibrium schedule by the other lobby unchanged). We do not engage in this exercise because this issue is not central for our analysis.
} 
consumers conditional on the parking fee. After considering the first-best policy as a benchmark, we then study lobbying and the government's decision on how to set the fee.

\subsection{Behavior of consumers and firms}

Given the parking fee $t$, consumers maximize utility, generating demands as described in (8) and (9). Downtown retailers are price taking firms so that, in equilibrium, each sells a quantity $q_{A}$ such that price is equal to marginal cost; hence, using (1), we have

$$
p_{A}=q_{A} .
$$

Replacing (16) in (7) and using (8) and (9), we can rewrite demands as follows:

$$
\begin{array}{ll}
q_{A}=\frac{\min \left[p_{B}, \beta y\right]+\beta-t}{2 \beta+1}, & \\
q_{B}=\frac{\beta+1+t-p_{B}}{2 \beta+1}, & q_{C}=0, \quad \text { if } p_{B} \leq \beta y, \\
q_{B}=0, & q_{C}=\frac{\beta+1+t-\beta t}{2 \beta+1},
\end{array}
$$

Given the demand function in (18), how will the suburban store B set its price? If the extra travel cost $\beta y$ to $\mathrm{C}$ is large so that $p_{B} \leq \beta y$, then no city consumer will shop there and $\mathrm{B}$ enjoys quite some market power. It would maximize its profit on all consumers that do not shop downtown. This profit is given by $p_{B} \frac{\beta+1+t-p_{B}}{2 \beta+1}$. Unconstrained profit maximization yields $p_{B}=\frac{\beta+t+1}{2}$. But, of course, $p_{B}$ is bounded from above by the extra cost a consumer incurs to buy at a store in C instead: if $\mathrm{B}$ charged $p_{B}>\beta y$, it would lose all customers.

The above discussion therefore establishes that:

$$
p_{B}=\min \left[\frac{\beta+t+1}{2}, \beta y\right] \text {. }
$$

Not surprisingly, (19) implies that pricing decisions by the suburban store B depend on how intense the competition is that it experiences from stores at C; moreover, it depends on the parking fee charged in equilibrium. Note the interpretation of $\beta y$, the extra travel cost for a shopper deciding to shop in $\mathrm{C}$ rather than B. Clearly, it implicitly captures the strength of the competitive pressure the suburban store B experiences from rival stores at C. The smaller it is, the easier it is easy for consumers who do not shop downtown to access alternative suppliers, and the lower the price that B is able to charge.

In order to streamline the exposition, it will be useful to distinguish two cases. We first proceed on the assumption that $\beta y \leq \frac{\beta+1}{2}$; using (19), this ensures that $p_{B}=\beta y$. It reflects the plausible 
situation in which store B's pricing behavior is relatively strongly restricted by the presence of competing stores at C. The case where $\beta y>\frac{\beta+1}{2}$ turns out to be much easier; it is briefly analyzed afterwards.

Given our assumption, we can write prices, quantities and profits in equilibrium as

$$
\begin{aligned}
& q_{A}=\frac{\beta-t+\beta y}{2 \beta+1}, \quad q_{B}=\frac{\beta+t+1-\beta y}{2 \beta+1}, \quad q_{C}=0, \\
& p_{A}=\frac{\beta-t+\beta y}{2 \beta+1}, \quad p_{B}=\beta y, \\
& \pi_{A}=\frac{1}{2}\left(\frac{\beta-t+\beta y}{2 \beta+1}\right)^{2}, \quad \pi_{B}=\beta y \cdot \frac{\beta+t+1-\beta y}{2 \beta+1} .
\end{aligned}
$$

Note that the setup of the model implies that the equilibrium quantities $q_{A}$ and $q_{B}$ in (20) must lie within the interval $[0,1]$. This imposes the following constraint on the parking fee:

$$
0 \leq t \leq \beta+\beta y \equiv \bar{t} .
$$

We assume throughout that (23) holds ${ }^{15}$.

Straightforward comparative statics suggest that a higher parking fee in the downtown commercial district penalizes retailers there: as shown by (20)-(22) their demands and profits decline. Demand shifts to store B in the suburbs; its profits increase. We can therefore expect downtown retailers to lobby against the parking fee. On the contrary, if store B lobbies, we expect it to be in favor of high fees. As will become clear below, what turns out to be crucial for the outcome is the extent to which each lobby is willing to promise the government additional contributions for a marginal change in the parking fee (i.e. the "steepness" of the contribution schedule).

\subsection{No-lobbying benchmark.}

Assume the government disregards lobbies' contributions, i.e., $\eta=1$ and $W_{G}=S W$ in (13). To find the optimal allocation, we maximize (12) with respect to $q_{A}$ and use (9). This yields

$$
q_{A}^{*}=\frac{\beta-e}{2 \beta+1}, \quad q_{B}^{*}=\frac{\beta+e+1}{2 \beta+1}, \quad q_{C}^{*}=0 .
$$

The socially optimal allocation is such that $q_{C}=0$ because the extra travel cost $\beta y$ is a pure deadweight loss. Therefore, optimality requires that, conditional on shopping in the suburbs, city consumers choose B. Note that a positive number of consumers that shop downtown requires that the

\footnotetext{
${ }^{15}$ Any market equilibrium where $t>\bar{t}$ is identical to one where $t=\bar{t}$. We then have $q_{A}=0$ and $q_{B}=1$ : when the parking fee is equal to or higher than $\bar{t}$, all consumers shop in the suburbs and none shops downtown.
} 
external cost of car trips downtown is not exceedingly large, that is, $e<\beta$. If this condition does not hold, all consumers shop only in the suburbs. This would imply that the optimal fee $t^{*}$ is not well defined, as any fee would be optimal as long as it is large enough that no consumer shops downtown. We therefore proceed assuming $e<\beta$.

Comparing (24) and the equilibrium quantities in (20), we immediately find that the parking fee

$$
t^{*}=e+\beta y,
$$

implements the optimum. The socially optimal fee $t^{*}$ is equal to the external cost $e$ plus the margin $\beta y$ that the suburban store $\mathrm{B}$ charges. To see the intuition, note that there are two market failures: the external cost of car trips to the downtown commercial district, and the market power of store B. In general, correcting two market failures requires two instruments; for instance, a parking fee could be combined with a linear subsidy (either directly to store B or to consumers that shop there). However, in the setting of our model, the set of government instruments can harmlessly be restricted to $t$. Our assumption that all consumers buy one unit of the retail good implies that the first best allocation can be implemented with any linear combination of $t$ and a linear subsidy, including one that equals zero.

\subsection{Lobbying and parking policy formation}

Suppose now that the government cares for the support of lobbies, i.e. $\eta<1$. From (22), we know that $\pi_{A}$ and $\pi_{B}$ are decreasing and increasing in $t$, respectively. It follows that the suburban store B will promise the government a contribution schedule $L_{B}(t)$ that increases in $t$; the opposite holds for the schedule $L_{A}(t)$ proposed by the lobby representing downtown retailers.

Let $t^{e}$ be the parking fee implemented in equilibrium, and assume all lobbying contributions are positive ${ }^{16}$. Using (13) and (15) it then follows that $t^{e}$ maximizes the objective function:

$$
W_{G}=\eta S W+(1-\eta) \sum_{i=A, B}\left(\pi_{i}-\phi_{i}\right) .
$$

The first-order condition (recall that the $\phi_{i}, i=A, B$ are constant) is

$$
\frac{\partial W_{G}}{\partial t}=\eta \frac{\partial S W}{\partial t}+(1-\eta)\left(\frac{\partial \pi_{A}}{\partial t}+\frac{\partial \pi_{B}}{\partial t}\right) \leq 0,
$$

\footnotetext{
${ }^{16}$ This is indeed the case in equilibrium, except when $t^{e}$ is a corner solution (i.e. equal to either zero or $\bar{t}$ ). Specifically, when $t^{e}=0$, B's contribution is zero. To see why, consider that, if it positive, B's contribution is increasing in $t$. Thus, if the government adopts $t^{e}=0$ when $\mathrm{B}$ provides a positive contribution, it must adopt the same fee when B's contribution is zero (given the contribution schedule promised by A). Hence, the best response by B is to provide no contribution. Similarly, A's contribution is zero when $t^{e}=\bar{t}$.
} 
where equality holds for any positive $t^{e}$. To facilitate the interpretation, we work out the first term on the right-hand side of (27). Differentiating (12) with respect to $t$, noting that in equilibrium $p_{B}=\beta y$ so that $I_{P_{B}>\beta y}=0$, we have:

$$
\frac{\partial S W}{\partial t}=\left(\beta-e-(2 \beta+1) q_{A}\right) \frac{\partial q_{A}}{\partial t} .
$$

Then use the demand function for $q_{A}$ as given in (20) and the first-best parking fee defined by (25) to obtain:

$$
\frac{\partial S W}{\partial t}=\left(t-t^{*}\right) \frac{\partial q_{A}}{\partial t}
$$

Finally, substitute this result in (27) and assume an internal solution. The equilibrium parking fee $t^{e}$ then satisfies the first-order condition:

$$
\frac{\partial W_{G}}{\partial t}=\eta\left(t^{e}-t^{*}\right) \frac{\partial q_{A}}{\partial t}+(1-\eta)\left(\frac{\partial \pi_{A}}{\partial t}+\frac{\partial \pi_{B}}{\partial t}\right)=0 .
$$

Although the derivatives of profit in (28) themselves depend on the parking fee, the expression does have a very intuitive interpretation. It suggests that the difference between the equilibrium parking fee $t^{e}$ and the socially optimal fee $t^{*}$ depends on two factors. First, it depends on the extent to which the government cares for social welfare, captured by $\eta$. The more politicians value the support of lobbies (i.e. the smaller is $\eta$ ), the more they are willing to deviate from the welfaremaximizing policy. Second, it depends on the effect of a higher parking fee on industry profits, i.e. $\frac{\partial \pi_{A}}{\partial t}+\frac{\partial \pi_{B}}{\partial t}$. A higher parking fee reduces profits of downtown retailers and raises that of the suburban store (see (22) above), so what matters is whether the profit decline for downtown retailers is smaller or larger than the increase in profit for the suburban store.

To illustrate, suppose that a marginal increase in the fee reduces downtown retailers' profit substantially, but yields little extra profit for the suburban store B. Then the former will be willing to offer a relatively large extra contribution to the city government in order to obtain a reduction in the fee. In this sense, they will lobby much more intensely than store B. In that case, (28) suggests that the equilibrium fee will be less than socially optimal. If on the contrary the suburban store were to have a substantial gain from high downtown parking fees and the losses to downtown retailers were small, the latter would not lobby intensively and fees above the social optimum may result.

The sign of the term $\frac{\partial \pi_{A}}{\partial t}+\frac{\partial \pi_{B}}{\partial t}$ can be given further interpretation. Denote the profit margin per unit sold for retailers of type $i$ by $M_{i}$. Specifically:

$$
M_{i} \equiv p_{i}-A V C_{i}, \quad i=A, B,
$$


where $A V C_{i}$ is average variable cost. Using (1), (20) and (21), we then have:

$$
M_{A}=\frac{\beta-t+\beta y}{2(2 \beta+1)} .
$$

Similarly, since $p_{B}=\beta y$ and noting that by assumption $A V C_{B}=0$, it follows that:

$$
M_{B}=p_{B}=\beta y \text {. }
$$

Substituting prices (as given by (20)) in (29), and using the expressions for $M_{A}, M_{B}$ just derived, it is then straightforward to show:

$$
\frac{\partial \pi_{A}}{\partial t}+\frac{\partial \pi_{B}}{\partial t}<0 \Leftrightarrow M_{B}<2 M_{A}
$$

This expression says that raising the parking fee reduces profits of downtown retailers more than that it increases profits of the suburban store if and only if the per-unit margin of the former is sufficiently large relative to that of the latter. In that case B's incentive to lobby for a marginal increase in $t$ is weaker than the incentive of downtown retailers to lobby against it. An analogous but opposite argument can be developed in the case the profit margin of a downtown retailer is much smaller, so that $M_{B}>2 M_{A}$.

Although the insights obtained from (28) are quite intuitive, it seems instructive to derive a closed-form solution for the equilibrium parking fee, expressing it as a function of model parameters only. Assuming that the objective function is concave in $t$ and focusing on an internal solution, we show in Appendix 2 that the lobbying process yields (corner solutions are discussed below; the case of a non-concave objective function is briefly discussed in Appendix 2):

$$
t^{e}=t^{*}+\frac{(1-\eta)[e-\beta+\beta y(1+2 \beta)]}{2 \eta(\beta+1)-1}
$$

where $t^{*}=e+\beta y$ is the socially optimal fee, see above. The denominator is positive by the secondorder condition. Equation (30) immediately implies that $t^{e}<t^{*}$ if and only if:

$$
\beta y<\frac{\beta-e}{2 \beta+1}
$$

As mentioned before, $\beta y$ captures the suburban store B's profit margin, measuring its market power (see above). Similarly, the right-hand side can be related to the profit margin of downtown retailers, evaluated at the socially optimal fee. To see this, it suffices to evaluate (29) for $t^{*}=e+\beta y$.

Summarizing our findings, we therefore have: 


$$
t^{e}<t^{*} \Leftrightarrow \beta y<\frac{\beta-e}{2 \beta+1} \Leftrightarrow M_{B}<2 M_{A}\left(t^{*}\right)
$$

Note that we assumed $\beta y \leq \frac{\beta+1}{2}$ throughout this section. Since $\frac{\beta+1}{2}>\frac{1}{2}>\frac{\beta-e}{2 \beta+1}$ it follows that, depending on the parameters, the equilibrium fee may be either below or above the socially optimal one. It confirms earlier intuition. If the margin of the superstore is sufficiently small compared to that of downtown retailers, the latter lobby with greater intensity. As they favor low parking charges, the government then deviates from the welfare maximizing policy by setting the parking fee below $t^{*}$. By contrast, a large enough margin for the suburban store results in the parking fee being higher than optimal.

Simple differentiation of (30) also confirms (see the comments made surrounding (28)) that the extent to which the government deviates from the optimal policy depends on how much it cares for lobbying contributions. As we show in Appendix 2, $\frac{\partial t^{e}}{\partial \eta}>0$ if and only if $\beta y<\frac{\beta-e}{2 \beta+1}$. Interpretation is obvious. Suppose the parking fee adopted in equilibrium is lower than the socially optimal fee $t^{*}$. Then the more the government cares for the support of lobbies (the lower the weight $\eta$ of social welfare in its objective function) the lower the fee. Moreover, not surprisingly, lobbying contributions may be so important for the government that the parking fee adopted is a corner solution. For instance, we show in Appendix 2 that there is a cutoff value $\tilde{\eta}$ such that $t^{e}=0$ when $\beta y<\frac{\beta-e}{2 \beta+1}$ and $\eta \leq \tilde{\eta}$.

Finally, recall that we have proceeded so far assuming that $\beta y \leq \frac{\beta+1}{2}$. Now assume the distance to travel to $\mathrm{C}$ is much higher so that the competition the suburban store $\mathrm{B}$ experiences from stores at $\mathrm{C}$ is much less strong. Specifically, let $\beta y>\frac{\beta+1}{2}$ and remember that by (19) we have $p_{B}=\min \left[\frac{\beta+t+1}{2}, \beta y\right]$. This implies, therefore, that - as long as $\beta y>\frac{\beta+t+1}{2}$-- store $\mathrm{B}$ benefits when the government raises $t$. A higher parking fee downtown allows store B to charge a higher price, raising its incentive to lobby for a higher fee. Because of this, as we show in Appendix 2, in this case the equilibrium parking fee is always larger than the socially optimal one.

The following proposition summarizes our main findings.

\section{PROPOSITION 1:}

a. The equilibrium parking fee is below the socially optimal level if and only if the per-unit 
profit margin of the suburban store $B$ is sufficiently small in comparison to that of downtown retailers. More precisely:

$$
t^{e}<t^{*} \Leftrightarrow M_{B}<2 M_{A}\left(t^{*}\right) \Leftrightarrow \beta y<\frac{\beta-e}{2 \beta+1},
$$

where $M_{A}\left(t^{*}\right)$ is the per unit profit margin of downtown retailers evaluated at the socially optimal parking fee.

b. If the equilibrium parking fee is less than socially optimal then it is weakly decreasing in the government's sensitivity to lobbying contributions. For sufficiently low $\eta$, the parking fee is zero. Specifically, there is a cutoff $\tilde{\eta}$ such that if $\eta \leq \tilde{\eta}$ we have $t^{e}=0$.

c. The equilibrium parking fee can be higher than the socially optimal level if and only if the per-unit profit margin of the suburban store $B$ is sufficiently large relative to that of downtown retailers. The fee is then weakly increasing in the government's sensitivity to lobbying contributions.

In many real-world cities, large suburban retail establishments dominate local markets and sell goods at relatively small margins (Foster et al., 2006; Basker, 2007). By contrast, the scale of downtown retailers is typically smaller, but they charge larger mark-ups. Our findings suggest that this has implications for downtown parking fees. If the suburban store's margin is small compared to that of downtown retailers, a dollar paid to the government to "buy" a marginal change in the parking fee produces a bigger change in profits for the latter than for the former. Thus, downtown retailers (as a whole) lobby with greater intensity in the sense that they are willing to offer the government a "steeper" schedule of payments. As they favor low parking charges, the government then deviates from the welfare maximizing policy by setting the parking fee below $t^{*}$. The extent of this deviation depends on how much lobbying contributions matter in the government's objective function.

\section{Differentiated goods and multiple-stop shopping}

The baseline model assumes that downtown retailers and suburban stores sell the same set of goods. In practice, however, they sell different (though possibly overlapping) ranges of products. This implies that consumers who want to enjoy the whole variety on the market may patronize both the downtown district and the suburbs (i.e., they engage in "multiple-stop shopping”). For instance, some consumers may do their basic grocery shopping at a suburban store and then buy special delicacies downtown. Or they may do their shopping in a suburban mall and go downtown to eat out or watch a movie. In this section, we extend the model to include these possibilities. 
Setup. We retain the setup of the baseline model of Section 2, except for the assumption that downtown retailers and suburban stores sell differentiated goods. More precisely, we consider three goods: $d, s$ and $f$. Goods $d$ and $s$ can be acquired only from downtown retailers and from suburban stores, respectively; good $f$ is instead available at both types of outlets. To simplify the analysis, we impose some extra structure on the problem.

First, we assume that each downtown retailer sells only one type of good: either $f$ or $d$, but not both. We denote the first type of retailers by subscript 'A, $f^{\text {' }}$ and the second by subscript ' $\mathrm{A}, d^{\text {' }}$. There is a unit mass of each type of downtown retailers and, as before, they are price-takers. The profit function of a downtown retailer is

$$
\pi_{A, k}=p_{A, k} q_{A, k}-\frac{q_{A, k}^{2}}{2}, \quad k=d, \mathrm{f},
$$

where $p_{A, \mathrm{~d}}\left(p_{A, \mathrm{f}}\right)$ is the price of good $d$ (respectively $f$ ) at downtown retailers, and $q_{A, \mathrm{~d}}\left(q_{A, \mathrm{f}}\right)$ are the corresponding quantities.

Second, suburban stores are multi-product firms: each sells both good $f$ and $s$. We retain the assumption of constant marginal costs for suburban stores (set to zero for simplicity). We denote by $p_{B, \mathrm{~s}}\left(p_{B, \mathrm{f}}\right)$ the price of good $s(f)$ at store B. As in the baseline model, we assume $p_{\mathrm{C}, \mathrm{S}}=p_{\mathrm{C}, \mathrm{f}}=0$ at suburban stores in C.

Third, consumers may shop (i) only in the downtown commercial district, (ii) only at suburban stores (these two cases amount to one-stop shopping), or (iii) they may shop at both locations (multiple-stop shopping). The advantage of this latter option is that it allows to consume the entire variety of goods available on the market. The drawback is of course the additional travel cost that has to be incurred.

Fourth, we assume that all consumers buy the "common" good $f$ but, if they visit a particular market place (i.e., either the downtown commercial district or suburban stores) they always buy the good which is exclusively available there. For example, if a consumer visits only downtown retailers, she buys $f$ and $d$. If she visits only the suburbs, she buys $f$ and $s$. If the consumer visits both marketplaces, she buys both $d$ and $s$; on top of that, she also buys $f$, though only where it is cheaper. We return to this last point below.

Market equilibrium. Suppose a consumer located in position $x$ visits only the downtown commercial district. This produces the following utility

$$
U(x, A)=V_{d}+V_{f}-p_{A, \mathrm{~d}}-p_{A, \mathrm{f}}-\beta x-t,
$$

where $V_{d}$ and $V_{f}$ are the gross utilities of consuming good $d$ and $f$, respectively. Similarly, a consumer shopping exclusively at the suburban store B gets utility 


$$
U(x, B)=V_{s}+V_{f}-p_{B, s}-p_{B, \mathrm{f}}-\beta(1-x) .
$$

As in the baseline model, a consumer will prefer $\mathrm{B}$ over $\mathrm{C}$ if and only if $p_{B, S}+p_{B, C} \leq \beta y$ holds. To avoid repetition, we anticipate that this condition is satisfied (we show below that this holds true in equilibrium). Hence, as in the baseline model, all consumers of the city that shop at a suburban store choose B rather than $\mathrm{C}$.

Finally, the utility obtained by a consumer located at $x$ and shopping in both commercial districts depends on where she buys good $f$. If she buys it at store $B$, her utility is

$$
V_{d}+V_{s}+V_{f}-p_{A, \mathrm{~d}}-p_{B, \mathrm{~s}}-p_{B, \mathrm{f}}-\beta-t
$$

If, instead, she buys good $f$ downtown, she gets utility

$$
V_{d}+V_{s}+V_{f}-p_{A, \mathrm{~d}}-p_{B, \mathrm{~s}}-p_{A, \mathrm{f}}-\beta-t .
$$

Direct comparison shows that, conditional on visiting both retail areas, the consumer will buy good $f$ at the suburban store $\mathrm{B}$ if and only if $p_{B, \mathrm{f}} \leq p_{A, \mathrm{f}}$. Although the qualitative results of this section do not depend on this condition, we focus, for brevity, on the case where good $f$ is indeed cheaper at suburban stores than downtown. This is probably the most likely scenario in reality. We will nonetheless discuss the results in the opposite case at the end of this section.

As in the baseline model, we implicitly assume that the gross utility $V_{f}$ of consuming the good available everywhere is always large enough that all consumers buy it. We also assume that $V_{s} \geq p_{B, \mathrm{~s}}$ and $V_{d} \geq p_{A, \mathrm{~d}}$. These conditions are sufficient to ensure that, conditional on visiting a marketplace, consumers buy the good that is exclusively available there.

Using the above utility definitions, we can identify the individual $\bar{x}$ who is indifferent between shopping only in the downtown commercial district and shopping in the suburbs as well:

$$
\bar{x}=\frac{\beta+p_{B, \mathrm{f}}-p_{A, \mathrm{f}}-\left(V_{s}-p_{B, \mathrm{~s}}\right)}{\beta} .
$$

Analogously, the individual in $\overline{\bar{x}}$, indifferent between visiting only the suburban store B and shopping both downtown and at $\mathrm{B}$, is found as

$$
\overline{\bar{x}}=\frac{V_{d}-p_{A, \mathrm{~d}}-t}{\beta} .
$$

We assume that $0 \leq \bar{x}<\overline{\bar{X}} \leq 1$. This condition means that there is at least one consumer visiting both the downtown commercial district and suburban stores, although there may not be consumers that visit only the downtown district or only the suburbs. However, we restrict attention to parameter values such that $\overline{\bar{x}}<1$ in the optimal allocation. Specifically, the external cost $e$ is large enough that 
it is not socially optimal to have all consumers shop downtown. ${ }^{17}$ These assumptions imply some restrictions on parameters, which we describe in Appendix 3.

We illustrate the spatial setting with multiple-stop shopping in Figure 3 below. The intuition underlying the figure is simple: conditional on shopping in one area, the extra cost of visiting the other one is larger the closer the consumer's position to the edges of the city. As a result, consumers located close to the edges are less likely to engage in multiple-stop shopping than those located towards the middle.

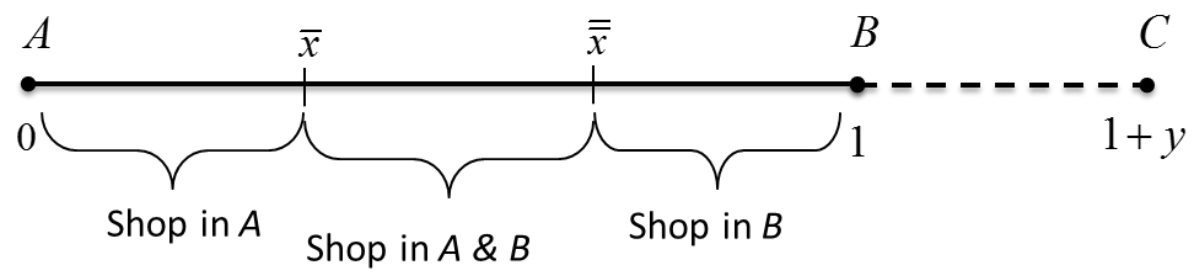

\section{Figure 3: equilibrium with differentiated goods and multiple-stop shopping}

Turning to the analysis of the equilibrium quantities (conditional on $t$ ), we begin with the downtown retailers that sell good $d$. Their demand is given by all consumers who visit the downtown commercial district (irrespectively of whether they also shop in the suburbs). As for downtown retailers that sell good $f$, they only serve consumers that exclusively visit the downtown district, because all those who visit B buy good $f$ there. Finally, the suburban store B sells goods $f$ and $s$ to all consumers that visit it (recall that we are assuming $p_{B, \mathrm{f}} \leq p_{A, \mathrm{f}}$ ). Given these insights, we show in Appendix 3 that equilibrium quantities can be written as ${ }^{18}$

$$
q_{d}=\overline{\bar{x}}=\frac{V_{d}-t}{\beta+1}, \quad q_{A, \mathrm{f}}=\bar{x}=\frac{\beta+\beta y-V_{s}}{\beta+1}, \quad q_{B, \mathrm{f}}=q_{B, \mathrm{~s}}=1-\bar{x}=\frac{1+V_{s}-\beta y}{\beta+1} .
$$

Equilibrium prices and profits are:

$$
\begin{array}{lll}
p_{A, \mathrm{f}}=\frac{\beta+\beta y-V_{s}}{\beta+1}, & p_{\mathrm{A}, \mathrm{d}}=\frac{V_{d}-t}{\beta+1}, & p_{B, \mathrm{~s}}+p_{B, \mathrm{f}}=\beta y, \\
\pi_{A, \mathrm{f}}=\frac{1}{2}\left(\frac{\beta+\beta y-V_{s}}{\beta+1}\right)^{2}, & \pi_{A, \mathrm{~d}}=\frac{1}{2}\left(\frac{V_{d}-t}{\beta+1}\right)^{2}, & \pi_{B}=\beta y \cdot \frac{1+V_{s}-\beta y}{\beta+1} .
\end{array}
$$

It is important to note from (35) and (37) that demand and profits of the suburban store B are independent of the parking fee $t$. The same goes for downtown retailers selling $f$. The reason is that

\footnotetext{
${ }^{17}$ If this condition did not hold, a welfare-maximizing government would have no reason to restrict access to the downtown district via the parking fee, given that all consumers should shop there in the optimum.

${ }^{18}$ We present these quantities under the implicit assumption that $\beta+\beta y>V_{s}$, i.e. $\bar{x}>0$. This is only to ease exposition. As we show in Appendix 3, $\bar{x}=0$ (i.e., all consumers shop in the suburbs) if this condition does not hold, but the results to follow do not change because the profit of store B does not depend on $t$.
} 
the marginal consumer $\bar{x}$ is indifferent between shopping only downtown and also shopping in the suburbs. Because the downtown parking fee $t$ is paid in both cases, it does not affect his/her decision. In other words, although some of the consumers that shop at B may stop buying good $d$ downtown in response to a higher parking fee, they will not stop shopping at B. Hence, B's total demand is unaffected. In contrast, profits of downtown retailers selling $d$ are decreasing in $t$. The reason is that the marginal consumer $\overline{\bar{X}}$ is indifferent as to whether to shop only in the suburbs and shop downtown as well. A higher parking fee induces her/him to avoid the latter alternative.

These observations have two important implications. First, as we show in Appendix 3, the socially optimal parking fee is equal to the external cost

$$
t^{*}=e \text {. }
$$

To understand this, note that, as in the baseline model, there are two market failures: the external cost of car trips downtown and the market power of store B. To implement the social optimum, in principle the government needs two instruments: a parking fee and a subsidy to consumers shopping in B. However, this latter instrument is not available in our model, and a welfare-maximizing government cannot do better than to implement $t=e$. There is no reason to deviate from this parking fee because, unlike in the baseline model, demand for B is independent of $t$, so the parking fee has no effect on market power.

Second, turn to the implications of lobbying and the political decision-making process for the parking fee. From (37), we immediately conclude that, since their profit is strictly decreasing in $t$, downtown retailers selling good $d$ lobby against it. By contrast, no contributions come from store $\mathrm{B}$, since its profit is independent of $t$. Thus, unless the government is completely insensitive to lobbying contributions (i.e. $\eta=1$ ), it will implement a parking fee which is below the social optimum. We summarize as follows.

\section{PROPOSITION 2: Assume that some consumers engage in multiple-stop shopping, i.e., shop both downtown and in the suburbs. The equilibrium parking fee is such that $t^{e}<t^{*}=e$.}

The intuition is that when consumers are willing to shop both downtown and in the suburbs, the cost of traveling to the former does not affect the choice to shop in the latter. The demand faced by suburban stores includes consumers that only shop in the suburbs and consumers that also shop downtown (where they buy good $d$, which is not available at suburban stores). A higher parking fee downtown may induce some of them to stop shopping there, but has no effect on their choice to shop in the suburbs. As a result, the profit of suburban retailers does not depend on the parking fee. Consequently, while downtown retailers have a strong interest in making sure the government sets 
the parking fee as low as possible, the suburban store B has nothing to gain from preventing such outcome. Hence, the government sets the parking fee below the optimal level.

It is also worth noting that not all downtown retailers are equally sensitive to changes in the parking fee. Indeed, (37) suggests that, while those that sell the specific good $d$ are penalized by a higher $t$, those that sell good $f$, also available at suburban stores, are unaffected. The logic of this result is as follows: the demand for sellers of $d$ comes from consumers who shop either exclusively downtown or both there and in the suburbs. A higher parking fee will induce some the latter to stop shopping downtown. By contrast, demand for downtown retailers that sell $f$ is made exclusively of "captive" consumers, who are so close to downtown that their decision to shop (only) there is independent of $t$. Therefore, downtown retailers that sell more differentiated goods are more likely to oppose higher parking fees. This is to some extent counterintuitive, as one would expect retailers that are more exposed to competition from suburban stores to be more active in seeking government protection.

Finally, recall that we made our argument assuming that $p_{B, \mathrm{f}} \leq p_{A, \mathrm{f}}$. For completeness, we briefly comment on the opposite case. Suppose that consumers that visit both the downtown district and the suburban store buy good $f$ from downtown retailers. Note that demand for suburban store B would still be independent of $t$, for the same reasons as before. It follows that the result of Proposition 2 would not change. However, in one respect the implications do differ: downtown retailers selling good $f$ would be negatively affected by the parking fee and would therefore oppose it, contrary to the case where $p_{B, \mathrm{f}} \leq p_{A, \mathrm{f}}$.

\section{Lobbying by downtown residents}

It has been argued in the literature (see, e.g., Arnott, 2011, van Ommeren et al., 2014) that local residents within (or in the proximity of) commercial districts also have incentives to influence the government's decisions on local parking fees. To evaluate this issue, in this section we allow lobbying by central city residents. To specifically focus on the role of residents and the trade-offs they face with respect to parking fees, we will simplify the analysis in other respects. We explain this in more detail below.

Setup. We assume there is a number of residents within the downtown commercial district (i.e., in position $x=0$ ); their number is denoted $N_{R}$. They suffer some disutility $r>0$ (assumed constant) from each car trip to the downtown district by a non-resident. For example, we can think of $r$ as being the consequence of scarce parking capacity. Residents care for the availability of parking spaces in the proximity of their home: they can park for free, but they have to compete for limited space with 
shoppers from outside. Hence, their utility decreases with the number of parking spaces occupied by visitors. With a fixed total supply of parking spaces, a higher parking fee on visitors has an effect similar to that of a larger share of parking spaces reserved to residents. ${ }^{19}$

The disutility due to visitors of the shopping area is only part of the story, of course. There are also benefits of having shops in the central residential area. Residents in the proximity of downtown shopping streets may benefit from the presence of local retailers: it raises the vitality of the area they live in. Moreover, it may raise the value of houses located in the same neighborhood, which benefits homeowners. Furthermore, vacant shopping spaces are often associated with blight and urban decay, producing a negative externality on local residents.

For the above reasons, we assume the utility of a local resident is

$$
U^{R}=v N_{A}-r Q_{A},
$$

where $v>0$ and constant, and $N_{A} \in[0,1]$ is the number of active downtown retailers. Note that, for simplicity, we disregard consumption of the retail good by local residents themselves and thus ignore the surplus they may obtain from shopping. ${ }^{20}$ Under our assumptions, the number of visitors equals the aggregate quantity sold downtown. This is denoted $Q_{A}$. The utility of a non-resident shopper is unchanged with respect to the previous sections, i.e., it is as described in (4), (5) and (6).

Clearly, if $N_{A}$ were constant, local residents would simply want to reduce the number of external visitors as much as possible, and have extreme incentives to lobby for high parking fees. We will therefore treat $N_{A}$ as endogenous.

We assume that there is an opportunity $\operatorname{cost} \theta$ of operating a shop in area A, which is distributed uniformly across the population of downtown retailers $\theta \sim U[0,1]$. This opportunity cost may be justified as follows. First, as many downtown retailers are entrepreneurial or family-run businesses, $\theta$ may capture the quality of alternative job opportunities for the tenant: for instance, the older and less skilled she/he is, the lower the likelihood of finding alternative occupations that provide a comparable income. Second, may capture the land rent paid to landowners, which may vary even within the central commercial district, depending on the specific location of the shop. Given the above discussion, the profit of a retailer in the downtown commercial district can be written as

$$
\pi_{A}\left(N_{A}, \theta\right)=\max \left[p_{A} \frac{Q_{A}}{N_{A}}-\frac{1}{2}\left(\frac{Q_{A}}{N_{A}}\right)^{2}-\theta, 0\right] .
$$

\footnotetext{
${ }^{19}$ Evidence provided in Inci (2015) suggests that residential parking permits may well be the result of this kind of lobbying. There are of course other reasons why local residents may dislike car trips from outside visitors, such as noise and pollution.

${ }^{20}$ This assumption is not crucial. At the end of this section, we discuss how the results would be affected if it were relaxed.
} 
Observe that, for given $\theta, \pi_{A}\left(N_{A}, \theta\right)$ is decreasing in $N_{A}$.

Obviously, a downtown shop characterized by opportunity cost $\theta$ will be active if and only if the gross operating profit is non-negative, i.e. $p_{A} \frac{Q_{A}}{N_{A}}-\frac{1}{2}\left(\frac{Q_{A}}{N_{A}}\right)^{2}-\theta \geq 0$. Thus, denoting the opportunity cost of the 'marginal' retailer by $\bar{\theta}$ (i.e., this is the cost of the retailer that is indifferent between being and not being active in equilibrium), the number of shops $N_{A}$ is such that

$$
p_{A} \frac{Q_{A}}{N_{A}}-\frac{1}{2}\left(\frac{Q_{A}}{N_{A}}\right)^{2}=\bar{\theta}
$$

Our assumption that $\theta \sim U[0,1]$ implies that the number of active retailers (i.e., all those for which $\theta \leq \bar{\theta}$ ) equals $\bar{\theta}$. That is, $N_{A}=\bar{\theta}$.

Finally, to simplify the analysis, we will assume throughout this section that $y=0$. Hence, from (19), $p_{B}=\pi_{B}=0, \forall t$. This implies that, as in the baseline model, no consumer in the city shops in C. Furthermore, no suburban store lobbies the government, as their profit is independent of $t$. Therefore, only two lobbies need to be taken into account: downtown retailers (i.e., lobby A) and local residents (i.e., lobby R).

Aggregating consumer surplus (given in (10)), the utility of residents, retailer profits and external costs we obtain the following social welfare function (using $N_{A}=\bar{\theta}$ )

$$
S W=C S+N_{R} U^{R}-e Q_{A}+\int_{0}^{N_{A}} \pi_{A}\left(N_{A}, \theta\right) d \theta
$$

After straightforward simplifications, this can be rewritten as: ${ }^{21}$

$$
S W=V-\beta \frac{Q_{A}^{2}}{2}-\beta\left(1-Q_{A}\right)+\beta \frac{\left(1-Q_{A}^{2}\right)}{2}-\left(e+r N_{R}\right) Q_{A}+v N_{R} N_{A}-\frac{1}{2} \frac{Q_{A}^{2}}{N_{A}}-\frac{N_{A}^{2}}{2} .
$$

Market equilibrium. The equilibrium condition that price equals marginal cost implies $p_{A}=\frac{Q_{A}}{N_{A}}$. Recalling that $p_{B}=0$, the equilibrium prices, quantities and profits - as functions of the parking fee and the number of retailers in A -- are easily obtained as: ${ }^{22}$

\footnotetext{
${ }^{21}$ It can be verified that $S W$ is a concave function of $t$.

${ }^{22}$ As in the previous section, we assume equilibrium quantities are strictly positive.
} 


$$
\begin{array}{rlrl}
Q_{A} & =\frac{(\beta-t) N_{A}}{2 \beta N_{A}+1}, & Q_{B}=\frac{1+(\beta+t) N_{A}}{2 \beta N_{A}+1}, \\
p_{A}=\frac{\beta-t}{2 \beta N_{A}+1}, & p_{B}=0, \\
\pi_{A}\left(N_{A}, \theta\right) & =\max \left[\frac{1}{2}\left(\frac{Q_{A}}{N_{A}}\right)^{2}-\theta, 0\right], & & \pi_{B}=0 .
\end{array}
$$

Some preliminary insights easily follow. First, in Appendix 4 we show, consistent with intuition, that a higher parking fee reduces the number of active downtown retailers in equilibrium. We specifically find

$$
\frac{\partial N_{A}}{\partial t}=\frac{\frac{\partial Q_{A}}{\partial t}}{\frac{1}{2}\left(\frac{Q_{A}}{N_{A}}\right)^{2}+N_{A}}<0
$$

Second, the total profit made by downtown retailers is strictly decreasing in the parking fee as well. We find (see Appendix 4):

$$
\frac{d \int_{0}^{N_{A}} \pi_{A}\left(N_{A}, \theta\right) d \theta}{d t}=N_{A} \frac{\partial N_{A}}{\partial t}<0 .
$$

Hence, as in previous sections, downtown retailers will lobby against the fee.

Third, it is useful to establish the trade-off faced by a resident of the central shopping area. Differentiating her utility $U^{R}$ as given in (38) with respect to the parking fee $t$ gives, after simple derivations

$$
\frac{d U^{R}}{d t}=v \frac{\partial N_{A}}{\partial t}-r \frac{d Q_{A}}{d t}=v \frac{\partial N_{A}}{\partial t}+r\left(\frac{N_{A}}{2 \beta N_{A}+1}\right)\left[1-\frac{Q_{A}}{\left(N_{A}\right)^{2}} \frac{\partial N_{A}}{\partial t}\right] .
$$

Not surprisingly, the sign of this effect is theoretically ambiguous: residents like high parking fees on outside visitors, but they do like local shops to stay (and this is an incentive to keep parking fees low). The previous expression can be rearranged to obtain that

$$
\frac{d U^{R}}{d t}<0 \Leftrightarrow \frac{v}{r}>\left(\frac{N_{A}}{2 \beta N_{A}+1}\right)\left(\frac{Q_{A}}{N_{A}^{2}}-\frac{1}{\frac{\partial N_{A}}{\partial t}}\right) .
$$

The utility of central residents is decreasing in the parking fee if the value attached to the vitality of the central city (captured by the presence of many downtown retailers) is large enough. By contrast, it is increasing in the parking fee if the external cost of car trips by visitors $r$ is large. It can be verified 
that the right hand side of (47) is decreasing in $t$. This implies that if (47) is satisfied for $t=0$, local residents' utility will be decreasing for any value of $t$. Hence,

$$
\frac{v}{r}>\left.\left(\frac{N_{A}}{2 \beta N_{A}+1}\right)\left(\frac{Q_{A}}{N_{A}^{2}}-\frac{1}{\frac{\partial N_{A}}{\partial t}}\right)\right|_{t=0} \Rightarrow \frac{d U^{R}}{d t}<0, \forall t .
$$

This is a sufficient condition for local residents to lobby against the parking fee. If (48) does not hold, residents may lobby either in favor or against the parking fee. Intuitively, this depends on the relative magnitude of $v$ and $r$.

The social optimum. To find the socially optimal parking fee we maximize (41) with respect to $t$ (the derivation is in Appendix 4). We find that the optimal parking fee $t^{*}$ satisfies

$$
\left(t^{*}-e-r N_{R}\right) \frac{d Q_{A}}{d t}+v N_{R} \frac{\partial N_{A}}{\partial t}=0
$$

Given that $\frac{d Q_{A}}{d t}$ and $\frac{\partial N_{A}}{\partial t}$ are quite complex functions of $t$, working out (49) in more detail does not lead to extra insights. However, it is easily seen that the optimal parking fee should not only account for the direct externalities produced by car trips of outside visitors ( $e$ and $r$ ), but also for the indirect externality $(v)$ due to the value that residents attach to the presence of downtown retailers in the proximity of their home.

Note that, unlike in the baseline model, the suburban stores have no market power by assumption. Hence, the parking fee should only be designed with the objective of making visitors internalize the external costs and benefits of driving to the downtown commercial district.

Lobbying. Consider lobbying and how the parking fee $t$ is determined. The contribution schedules of the two lobbies $i=A, R$ (retailers and local residents) are

$$
L_{A}(t)=\max \left[\pi_{A}(t)-\phi_{A}, 0\right], \quad L_{R}(t)=\max \left[U^{R}(t)-\phi_{R}, 0\right] . \quad \forall t
$$

As before, the objective function of the government is

$$
W_{G}=\eta S W+(1-\eta) \sum_{i=A, \mathrm{R}} L_{i} .
$$

The first-order condition of the government's optimization problem can be rewritten, using similar methods as before, to show that the resulting equilibrium parking fee $t^{e}$ satisfies:

$$
\frac{\partial W_{G}}{\partial t}=\eta\left(\left(t^{e}-e-r N_{R}\right) \frac{d Q_{A}}{d t}+v N_{R} \frac{\partial N_{A}}{\partial t}\right)+(1-\eta)\left(\frac{d \pi_{A}}{d t}+\frac{\partial U^{R}}{\partial t}\right) \leq 0
$$

with equality for an internal solution. Expression (50) suggests that the comparison between $t^{e}$ and 
the socially optimal fee $t^{*}$ hinges on the sign of $\frac{d \pi_{A}}{d t}+\frac{d U^{R}}{d t}$, the net effect of a marginal increase in the fee on retailer profits and utility of residents of the commercial district. As the sign of this term depends on $t$ itself, it is hard to establish it in general. We can nonetheless provide some interesting insights.

First, suppose that (48) holds: in words, local residents always dislike the parking fee. This is a sufficient condition for $\frac{d \pi_{A}}{d t}+\frac{d U^{R}}{d t}$ to be negative (for any value of $t$ ), so that (50) necessarily implies an equilibrium parking fee below the optimum: $t^{e}<t^{*}$. If local residents attach a high value to the vitality of the area where they reside, and if they therefore want to preserve downtown retailers, they will oppose parking fees on outside visitors. In that case, their interests coincide with those of the retailers themselves. This convergence of different special interests leads the government to implement a parking fee that is below the social optimum.

However, if local residents attach a high value to the disutility imposed by outside visitors, it may dominate their desire to keep many local shops. Then, (48) does not hold. In equilibrium residents may lobby for the parking fee (if $\frac{d U^{R}}{d t}>0$ ) or against it (if $\frac{d U^{R}}{d t}<0$ ). While it is not easy to provide clean analytical conditions for either case, it is intuitive that the former will take place if $r$ is large enough. By contrast, local retailers will always want the fee to be small (as $\left.\frac{d \pi_{A}}{d t}<0\right) .{ }^{23}$

We can therefore establish the following proposition:

PROPOSITION 3: Suppose residents care about the vitality of the downtown commercial district but also suffer disutility from outside visitors.

a. If preference for vitality is sufficiently strong relative to the disutility of searching for parking spaces (so that (48) holds), both downtown retailers and residents lobby against the parking fee. As a result, the fee is strictly below the socially optimal level.

b. If preference for vitality is relatively weak (so that (48) does not hold), residents may lobby in favor of parking fees (and will do so if the disutility of searching for parking is large) or against them, while retailers will always lobby against. The parking fee may be below or above the optimal level.

${ }^{23}$ Further analysis of the term $\frac{d \pi_{A}}{d t}+\frac{d U^{R}}{d t}$ using earlier results does not produce extra insights. The bottom line is simply that the outcome depends on the strength of (i) residents' disutility associated with more visitors of the local shopping area in A, (ii) residents concern for the attractiveness of the local downtown commercial district and (iii) the impact of higher parking fees on retailer profits and the number of retailers. 
Residents in the downtown district face a trade-off: increasing parking fees for outside visitors frees up parking spaces but also reduces business opportunities for local shops. As a result, the latter may decide to abandon the downtown district, reducing its attractiveness as a residential location as well. Thus, residents may oppose parking fees in order to protect local retailers. This is conceivably more likely in relatively small cities, where the number of outside visitors is limited, and so is the number of retailers. Exit of downtown shops may then quickly lead to an impoverished and blighted downtown area. Furthermore, local residents are probably less likely to face problems with congestion of parking than in large cities. In our model, this would be captured by a small $r$ and a high $v$. This makes the outcome described in Proposition 4.a more likely. Indeed, as some of the examples reported in the introduction suggest, in small cities residents often do take sides with local retailers in opposing parking fees (see footnote 3).

Things are probably different in larger cities, where the risk of exit of downtown retailers is likely to be smaller, given the greater number of visitors. Moreover, downtown commercial districts of large cities are more dynamic. Hence, exit of some downtown retailers probably has a smaller impact on residents' utility (i.e. small v). In contrast, space constraints are likely to be more severe, together with availability of reserved parking spaces for residents (high $r$ ). As a result, residents may support increasing parking fees on outside visitors. Van Ommeren et al. (2011, 2014) document some indirect evidence of this phenomenon for large shopping districts in the Netherlands, where residents pay significantly smaller parking fees than outside visitors.

Of course, our model is very simple and may not capture all the aspects that determine local residents' support, or lack thereof, for parking fees. It seems, however, that more elaborate and realistic frameworks would not yield very different qualitative results. For instance, we have ignored the surplus local residents may derive from shopping in the neighborhood they live in. In our model, if local residents were shoppers like the remainder of the population, except in extreme situations, they would patronize the downtown district. This would increase their distaste for the parking fee, especially if it reduces the number of shops (and, hence, competition). Furthermore, suppose downtown retailers sold different goods and store location were endogenous. The parking fee may then induce certain types of downtown retailers to cease operation in the downtown commercial district, either moving to the suburban retail area or simply exiting the local market. This would penalize centrally located consumers, who would either have to cease consuming goods sold by those who moved out, or travel all the way to B in order to purchase them. As in our simple framework, therefore, exit of retailers from the downtown district may reduce residents' support for tighter parking policy. 


\section{Extensions}

In this section we briefly point at some further extensions. For more details, we refer to the working paper (see De Borger and Russo (2015)). We first allow shoppers to use an alternative transport mode apart from the car; next we discuss the impact of the threat of entry of additional superstores in B on lobbying and parking fees.

First, reconsider the baseline model but assume that alternative means of transport are available to downtown shoppers, such as public transportation, biking or walking. If consumers respond to an increase in the cost of using cars by switching to another mode, one might intuitively expect that retailers in the downtown district suffer less from high parking charges and, thus, that they have weaker incentives to lobby. However, retailers only care for the parking fee to the extent that it affects the marginal consumer, i.e., the person indifferent between shopping in the suburb or in the downtown area. The validity of the reasoning above therefore depends on whether or not this consumer is a car user.

Consider public transport to the downtown area as an alternative model for purposes of concreteness. No public transport is available to the suburban store B; all consumers shopping there go by car. Assume that car travel entails smaller time costs (accounting for both in- and out-of-vehicle time costs) than public transport (see, e.g., Sasaki (1990) and Borck and Wrede (2008)) and that using cars for shop-related travel may be more convenient (e.g., in the case of bulky goods). Moreover, further assume that public transport generates no external costs. ${ }^{24}$

Within this stylized setting, it can be shown that two equilibrium patterns may result, as illustrated on Figure 4. At very low public transport fares, an equilibrium may imply that everyone shopping downtown uses public transport. The parking fee is such that this is the case. At sufficiently high fares, those closest to the center will use public transport, others will drive their cars; all shoppers in the suburbs go by car. In this case, the results of Proposition 1 do not change. In equilibrium, the parking fee may be above or below the socially optimal level, depending on the intensity of lobbying by retailers downtown and in $\mathrm{B}$.

\footnotetext{
${ }^{24}$ We ignore crowding externalities in public transport for simplicity. See, e.g., de Palma et al. (2015) and for an indepth analysis of this issue.
} 


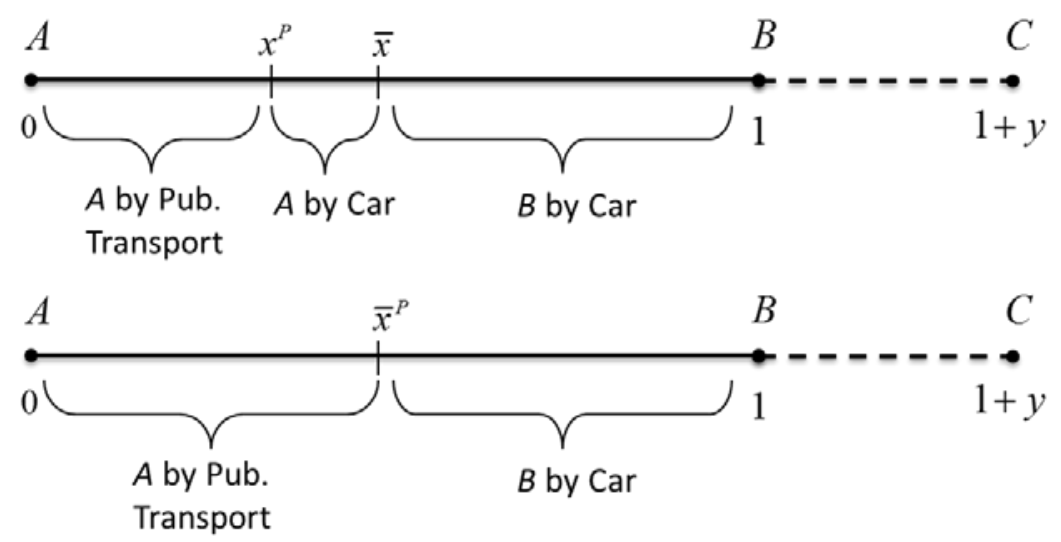

Figure 4: equilibria with public transportation. In the upper panel the cutoff $x^{P} \leq \bar{X}$; in the lower panel, $x^{P}>\bar{x}$.

Second, reconsider our baseline model under the threat of entry of additional suburban stores within the city market (i.e. in the same location as B or closer to the city center). This is a relevant scenario since, in reality, the big-box segment of the retail industry is characterized by rates of (net) entry that are non-negligible, and typically higher than the downtown retail segment (see Competition Commission, 2008 for the UK and Foster et al., 2006 for the US). Quite intuitively, entry of a new suburban store in (or in the proximity of) the city is a threat to incumbent retailers.

We have argued in Proposition 1 that when strong competitive pressure forces a suburban store to keep margins low, its incentive to support higher parking prices in the downtown commercial district is weak. However, even if competition from incumbents is lax, the mere threat of entry by a similar competitor may be enough to discourage a suburban store from supporting parking fees in the central area. Suppose an additional suburban store may decide to enter the market. Suppose also that it has some competitive advantage with respect to B (e.g. a more convenient location, some cost advantage or greater product quality or variety). ${ }^{25}$ As we have seen in the baseline model, equilibrium demand for B increases with the parking fee. As a result, the higher such fee, the greater the market share potentially available to the new entrant. Thus, raising the parking fee practically reduces barriers to entry for the new suburban store. Consequently, lobbying for the parking fee may be counterproductive for incumbents.

Summing up, all incumbent retailers have an interest in keeping a new suburban store out of the local market. If entry is a relevant threat, incumbent suburban stores may deliberately choose not to oppose underpricing of parking spaces in the downtown commercial district, even though they would if no such threat existed. They may thus prefer to let the government "protect” the downtown

\footnotetext{
${ }^{25}$ New entrants in the big-box segment are often adopters of cost-reducing innovations, such as ICT sales and inventory support (Basker, 2007).
} 
district (where less powerful rivals are located), for fear of entry of a much more threatening competitor. ${ }^{26}$ As long as the entry costs are not too large and externalities produced by automobile travel are significant, the resulting parking fee will typically be below the socially optimal level.

\section{Concluding remarks}

We have studied a spatial equilibrium model to study the political economy of pricing downtown parking space when special interest groups (urban and suburban retailers, local residents) lobby the city government. We find that in equilibrium very diverse lobbying patterns may result. Downtown stores may lobby in favor or against high parking fees, depending on profit margins in urban and suburban stores. In many realistic cases, for example when consumers engage in multiplestop shopping, large suburban stores will not lobby at all. The results of lobbying is that the local government underprices downtown parking if either (i) suburban stores sell at small enough margins compared to traditional downtown retailers, or (ii) some consumers shop both downtown and in the suburbs. Furthermore, we find that if exit of downtown retailers is not too strong a concern, residents lobby for higher parking fees on visitors. Otherwise, downtown residents lobby, together with downtown retailers, against parking fees.

As mentioned above, with minimal adaptation, one can interpret the parking fee in our model as a cordon toll to enter downtown. Many of the tolling schemes that have been implemented (or contemplated) by city governments encompass the traditional downtown commercial district. Similarly to parking fees, cordon tolls increase the cost of accessing the downtown commercial districts. As the evidence provided in the Introduction suggests, tolls have often met opposition by local retailers. Our model therefore provides an explanation to the low political acceptability of road pricing in cities.

Generally speaking, under the empirically most relevant conditions, the model predicts that governments will often underprice parking. Before concluding, it is useful to reflect briefly on how robust our findings are to relaxing some important assumptions of our model. First, we have ignored congestion. However, adding congestion to the model is unlikely to change the main results. Indeed, assuming the parking fee increases the generalized cost of travel to the downtown commercial district (despite curbing congestion), central city retailers would still dislike it. Second, in a more elaborate model, one could allow consumers to choose not only where to shop, but also how much time to spend shopping per visit (as in, e.g., Glazer and Niskanen, 1992). Assuming purchases increase at a decreasing rate with time per visit, and there is congestion of parking spaces, retailers may prefer a

\footnotetext{
${ }^{26}$ Ashiya (2000) provides a similar argument in a model of oligopolistic competition with horizontally differentiated products.
} 
positive parking fee (proportional to length of stay) to no fee at all, in order to raise customer turnover. However, it is not obvious that they would want a fee equal to or higher than the socially optimal level. ${ }^{27}$ Furthermore, the effect of the parking fee on profits conceivably depends on the degree of saturation of parking spaces. Evidence provided by Hymel (2014) suggests that even for very high levels of saturation, parking meter rates do not increase turnover and actually reduce profits for nearby retailers at lower (though still large) saturation levels.

Finally, we also ignored the distinction between curbside and garage parking. As shown by Inci and Lindsey (2015), modeling the interaction between providers of these two parking forms is important and may lead to counterintuitive outcomes. For simplicity, our model assumes that the government controls the price of all parking spaces in the commercial district. One may, of course, consider the possibility that the government controls only on-street parking, while garages set prices independently. Calthrop and Proost (2006) show that, as long as on- and off-street parking are perfect substitutes, in the competitive equilibrium prices are the same for both parking modes. ${ }^{28}$ Furthermore, many countries regulate pricing by parking garages in commercial districts, at least when their market power is large. Hence, our assumption can be considered a reasonable first-order approximation.

\footnotetext{
${ }^{27}$ After all, as the evidence provided in the introduction suggests, retailers' opposition to parking charges (and road tolls) is very common. It is possible that downtown retailers' associations systematically fail to understand the link between reduced parking fees and increased congestion, and therefore oppose fees even when they would benefit from them. Albeit plausible, we have not found evidence supporting this hypothesis.

${ }^{28}$ Kobus et al. (2013) find that drivers prefer parking on-street, but rather weakly: the willingness-to-pay to park on-street is 0.25 Euros per trip.
} 


\section{References}

Aghion, P. and M. Schankerman (2004). On the welfare effects and political economy of competitionenhancing policies. Economic Journal 114, 800-824.

Anderson, S. and A. de Palma (2004). The economics of pricing parking. Journal of Urban Economics 55 (1), 1-20.

Arnott, R. (2011). Parking Economics, in A. de Palma, R. Lindsey, E. Quinet, and R. Vickerman (eds.), Handbook of Transport Economics, Edward Elgar, 726-743.

Arnott, R. and J. Rowse (1999). Modeling Parking. Journal of Urban Economics 45, 97-124.

Arnott, R. and J. Rowse (2009). Downtown Parking in Auto City. Regional Science and Urban Economics 39, 1-14.

Arnott, R. and E. Inci (2006). An Integrated Model of Downtown Parking and Traffic Congestion, Journal of Urban Economics 60, 418-442.

Arnott, R., Inci, E. and J. Rowse (2015). Downtown curbside parking capacity. Journal of Urban Economics 86, 83-97.

Ashyia, M. (2000). Weak Entrants Are Welcome. International Journal of Industrial Organization, 18, 975-984.

Baldwin R. and F. Robert-Nicoud (2007). Entry and Asymmetric Lobbying: Why Governments Pick Losers. Journal of the European Economic Association 5, 1064-1093.

Basker, E. (2007). The Causes and Consequences of Wal-Mart's Growth. Journal of Economic Perspectives 21, 177-198.

Bent, E. and Singa, K. (2009). Modal Choices and Spending Patterns of Travelers to Downtown San Francisco, California: Impacts of Congestion Pricing on Retail Trade. Transportation Research Record 2115, http://dx.doi.org/10.3141/2115-09.

Bernheim, B. and M. Whinston (1986). Menu Auctions, Resource Allocation, and Economic Influence. Quarterly Journal of Economics 101, 1-31.

Borck, R. and M. Wrede (2005). Political economy of commuting subsidies. Journal of Urban Economics 57, 478-99

Borck, R. and M. Wrede (2008). Commuting Subsidies with Two Transport Modes. Journal of Urban Economics 63, 841-848.

Brandão, A., Correia-da-Silva, J. and J. Pinho (2014). Spatial competition between shopping centers. 
Journal of Mathematical Economics 50, 234-250.

Brueckner, J.K. and H. Selod (2006), The political economy of urban transport-system choice, Journal of Public Economics 90, 983-1005.

Canadian Convenience Store Association (2012). Annual Industry Report 2012.

Calthrop, E. and S. Proost (2006). Regulating on-street parking. Regional Science and Urban Economics 36, 29-48.

Chen, Z., and P. Rey, (2012). Loss Leading as an Exploitative Practice. American Economic Review, 102(7): 3462-82.

City of Copenhagen (2013). Are cyclists bad customers? Available at: http://velo-city2013.com/wpcontent/uploads/20130612_mariekastrup.pdf

Competition Commission (2008). The supply of groceries in the UK market investigation.

De Borger, B. and S. Proost (2012). A political economy model of road pricing. Journal of Urban Economics 71, 79-92.

De Borger, B. and A. Russo (2015), The political economy of pricing access to downtown commercial districts, CESIfo working paper 5294.

de Palma, A., Kilani, M. and S. Proost (2015). Discomfort in mass transit and its implications for scheduling and pricing. Transportation Research B: Methodological 71, 1-18

Eliasson, J. (2009). A cost-benefit analysis of the Stockholm congestion charging system. Transportation Research A 43, 468-480.

Federation of Small Businesses (2008). Keep Trade Local - Parking Policies for Sustainable Communities. Available at: http://www.fsb.org.uk/ktl.

Foster, L., Haltiwanger J., and C. J. Krizan (2006). Market Selection, Reallocation and Restructuring in the U.S Retail Trade Sector in the 1990s. Review of Economics and Statistics 88, 748-758.

Friends of the Earth (2006). Calling the Shots - How Supermarkets Get Their Way in Urban Planning. Available at: https://www.foe.co.uk/sites/default/files/downloads/calling_the_shots.pdf.

Glazer, A. and E. Niskanen (1992). Parking fees and congestion. Regional Science and Urban Economics 22, 123-132

Ghosh, A. and Meagher, K. (2014). Voting on infrastructure investment: the role of product market competition. Working paper, Australian National University.

Grossman, G.M. and E. Helpman (1994). Protection for Sale. American Economic Review 84, 833- 
850.

Grossman, G.M., Helpman E., and A. Dixit (1997). Common agency and coordination: General theory and an application to government policy making. Journal of Political Economy 105, 752-769.

Hasker, K. and E. Inci (2014). Free Parking for All in Shopping Malls. International Economic Review 55, 1281-1304.

Hymel, K. (2014). Do parking fees affect retail sales? Evidence from Starbucks. Economics of Transportation 3, 221-233.

Inci, E. and R. Lindsey (2015). Garage and Curbside Parking Competition with Search Congestion. Regional Science and Urban Economics 54, 49-59.

Inci E. (2015). A review of the economics of parking. Economics of Transportation 4, 50-63.

Jakle, J., Sculle, K., 2004. Lots of Parking: Land Use in a Car Culture. University of Virginia Press, Charlottesville.

Kobus, M.B.W., Gutiérrez-i-Puigarnau, E., Rietveld, P. and J. van Ommeren (2013). The on-street parking premium and car drivers' choice between street and garage parking. Regional Science and Urban Economics 43, 395-403.

Lagakos, D. (2009). "Superstores or mom and pops? Technology adoption and productivity differences in retail trade”. FRB of Minneapolis Research Department Staff Report 428.

Mingardo, G. and J. Meerkerk (2012). Is parking supply related to turnover of shopping areas? The case of the Netherlands. Journal of Retailing and Consumer Services 19, 195-201.

Molenda, I. and G. Sieg (2013). Residential Parking in Vibrant City Districts. Economics of Transportation 2, 131-139.

Reimers, V. (2013). Convenience for the car-borne shopper: Are malls and shopping strips driving customers away? Transportation Research A 49, 35-47.

Russo, A. (2013). Voting on Road Congestion Policy. Regional Science and Urban Economics 43, 707-724.

Sasaki, K., 1990. Income class, modal choice, and urban spatial structure. Journal of Urban Economics 27, 323-343.

Shoup, D.C. (2005). The High Cost of Free-parking, Planners Press, Chicago.

Small, K. and E. Verhoef (2007). The Economics of Urban Transportation, Routledge, London.

Smith, H. and D. Hay (2005). Streets, Malls and Supermarkets. Journal of Economics and 
Management Strategy 14, 29-59.

UK Department for Communities and Local Government (2013). The Future of High Streets, Progress since the Portas Review. Available at: https://www.gov.uk/government/uploads/system/uploads/attachment_data/file/211536/Future_of_Hi gh_Street_-_Progress_Since_the_Portas_Review_-revised.pdf

Uschev, P., Sloev, I. and J-F. Thisse (2015). Do We Go Shopping Downtown or in the Burbs? Why not both. Journal of Urban Economics 85, 1-15.

van der Waerden, P., Borgers, A., and H. Timmermans (2009). Consumer response to the introduction of paid parking in a regional shopping center. Transportation Research Record 2118, 16-23.

van Ommeren, J., Wentink, D. and J. Dekkers (2011). The real price of parking policy. Journal of Urban Economics 70.

van Ommeren, J., de Groote, J. and G. Mingardo (2014). Residential parking permits and parking supply. Regional Science and Urban Economics 45, 33-44. 


\section{Appendix 1: Truthful contribution schedules}

We adapt Lemma 2 of Bernheim and Whinston (1986) (see also Grossman and Helpman, 1994, Proposition 1) to our setup. This Lemma states that the following four conditions are necessary and sufficient for a couple of contribution schedules $L_{i}(t), i=A, B$ and a policy $t$ chosen by the government to be a Subgame Perfect Nash Equilibrium of the policy game:

1. $L_{i}(t) \leq \pi_{i}(t), \mathrm{i}=\mathrm{A}, \mathrm{B}$

2. $t$ maximizes $W_{G}$

3. $t$ maximizes $W_{G}+\pi_{i}(t)-L_{i}(t), \mathrm{i}=\mathrm{A}, \mathrm{B}$

4. $\forall i, \exists t^{0}{ }_{i}=\arg \max W_{G}$, s.t. $L_{i}\left(t^{0}{ }_{i}\right)=0$

Condition 1 states that the equilibrium policy is feasible. That is, it is such that the contribution paid by lobby $i$ in equilibrium is not greater than its total profit. Condition 2 states that the equilibrium policy maximizes the government's objective function. Condition 3 states that, for each lobby, in equilibrium the firm's net profit (after contributions) and the government's objective function are maximized. If the condition failed to hold, the lobby could reformulate its contribution schedule and induce the government to choose the jointly optimal policy and appropriate part of the surplus generated by the policy change. Finally, condition 4 requires that, for each lobby, there exists at least one policy $t^{0}{ }_{i}$ which maximizes the government's objective when $L_{i}\left(t_{i}^{0}\right)=0$ (given what the other lobby proposes). In other words, the contribution $L_{i}$ has to be zero for some policy $t$. Otherwise, the lobby could induce exactly the same government policy while decreasing the contribution $L_{i}$ for all $t$.

Given that contribution schedules are differentiable by assumption, conditions 2 and 3 imply, respectively, that $\frac{\partial W_{G}}{\partial t}=0$ and (if $L_{i}$ is positive at $t$ ) $\frac{\partial \pi_{i}}{\partial t}-\frac{\partial L_{i}}{\partial t}+\frac{\partial W_{G}}{\partial t}=0$. Combining these expressions we have (14). We have therefore established that, when positive, contribution schedules are locally truthful in equilibrium. As in Bernheim and Whinston (1986) and Grossman and Helpman (1994), the notion of truthfulness can be extended to obtain a truthful contribution schedule as defined in (15) (see, Bernheim and Whinston, 1986, Theorem 1). 


\section{Appendix 2: Proof of Proposition 1}

As in the main body of the paper, we first restrict attention to the case $\beta y \leq \frac{\beta+1}{2}$. We begin by assuming that both lobbies, $A$ and $B$, provide positive contributions in equilibrium. We have shown in the main text that the derivative of the objective function with respect to the parking fee can then be written as:

$$
\frac{\partial W_{G}}{\partial t}=\eta\left(t-t^{*}\right) \frac{\partial q_{A}}{\partial t}+(1-\eta)\left(\frac{\partial \pi_{A}}{\partial t}+\frac{\partial \pi_{B}}{\partial t}\right)
$$

Rewriting $\frac{\partial \pi_{A}}{\partial t}$ and $\frac{\partial \pi_{B}}{\partial t}$ using (22), and noting that $t^{*}=e+\beta y$, we can reformulate (A2.1) to find:

$$
\frac{\partial W_{G}}{\partial t}=\frac{1}{(2 \beta+1)^{2}}[(1-2 \eta(\beta+1)) t+\eta(2 \beta+1)(e+\beta y)-(1-\eta) \beta(1-2 \beta y)]
$$

Let the objective function be concave in the parking fee and focus on interior solutions (corner solutions and non-concave objective functions are dealt with below). We can then set (A2.2) equal to zero and solve for the equilibrium fee $t^{e}$. We find after some algebra:

$$
t^{e}=\frac{\eta(2 \beta+1) t^{*}-(1-\eta) \beta(1-2 \beta y)}{2 \eta(\beta+1)-1}
$$

The second order condition for a maximum requires:

$$
\frac{\partial^{2} W_{G}}{\partial t^{2}}=\eta \frac{\partial q_{A}}{\partial t}+(1-\eta)\left(\frac{\partial q_{A}}{\partial t}\right)^{2}=-\eta \frac{1}{2 \beta+1}+(1-\eta)\left(\frac{1}{2 \beta+1}\right)^{2}<0 .
$$

It is easy to see that this implies

$$
2 \eta(\beta+1)-1>0
$$

Finally, using $t^{*}=e+\beta y$, we can rearrange (A2.3) and find have after simple algebra that:

$$
t^{e}-t^{*}=\frac{(1-\eta)[e-\beta+\beta y(1+2 \beta)]}{2 \eta(\beta+1)-1}
$$

To analyze how the equilibrium parking fee $t^{e}$ varies with $\eta$ (capturing the degree to which the government cares for social welfare), we differentiate (A2.5) to find:

$$
\frac{\partial t^{e}}{\partial \eta}=\frac{-[e-\beta+\beta y(1+2 \beta)][2(\beta+1)-1]}{[2 \eta(\beta+1)-1]^{2}}
$$

To interpret this note that, if $t^{e}<t^{*}$, we know $[e-\beta+\beta y(1+2 \beta)]<0$, see (A2.5). Moreover, we have 
$\eta \leq 1$ so that the inequality $2 \eta(\beta+1)-1>0$ automatically implies $2(\beta+1)-1>0$. It then immediately follows from (A2.5) that:

$$
\frac{\partial t^{e}}{\partial \eta}>0
$$

Hence, when $t^{e}$ is an interior solution below $t^{*}$, it is increasing in the weight $\eta$ the government places on social welfare. If the equilibrium fee is below the social optimum it will be lower the more the government cares about lobbying contributions.

Of course, this result also suggests that when the government's concern for social welfare is sufficiently low (a sufficiently low $\eta$ ) so that the solution is driven by intensive lobbying by downtown retailers to obtain low parking fees, a corner solution may result where the equilibrium parking fee is zero. This is indeed the case. Because $2 \eta(\beta+1)-1>0$ by assumption, it is easy to show that the derivative of the social welfare function with respect to the parking fee (A2.2) is negative for any $t \geq 0$ when $\eta(2 \beta+1)(e+\beta y) \leq(1-\eta) \beta(1-2 \beta y)$, that is, when:

$$
\eta \leq \tilde{\eta} \equiv \frac{\beta(1-2 \beta y)}{\beta y+\beta+(2 \beta+1) e} .
$$

This implies that $t^{e}=0$ when $\eta \leq \tilde{\eta}$.

For completeness sake, consider the case where the objective function is not concave. As it is assumed to be continuous and differentiable in $t$, the maximization problem must have a corner solution, i.e., we have either $t^{e}=0$ or $t^{e}=\bar{t}$. First, suppose $2 \eta(\beta+1)-1=0$ so that, see above, the second derivative of social welfare with respect to the fee is zero; the social welfare function is linear in $t$. Using $2 \eta(\beta+1)-1=0$ and $\beta y<\frac{\beta-e}{2 \beta+1}$ in the first-order derivative (A2.2), one obtains that the expression is always negative. As a result, the equilibrium fee must be such that $t^{e}=0$. Second, suppose $2 \eta(\beta+1)-1<0$ so that the objective function is convex. By analogy with the previous case, $t^{e}=0$ is the solution to the problem. Intuitively, the government is now even more sensitive to lobbying contributions (and less mindful of social welfare) than in the previous case, and it is even more inclined to adopt a zero fee, in response to A's contributions. If the objective function is not concave but $\beta y>\frac{\beta-e}{2 \beta+1}$, then we have by similar arguments that $t^{e}=\bar{t}$.

Finally, we consider the case $\beta y>\frac{\beta+1}{2}$. We show that this condition implies that industry profits increase in the parking fee $\left(\frac{\partial \pi_{A}}{\partial t}+\frac{\partial \pi_{B}}{\partial t}>0\right)$. As shown in the main body of the paper this in 
turn implies that the equilibrium fee is always larger than the socially optimal one. To get started, remember from (19) that $p_{B}=\min \left[\frac{\beta+t+1}{2}, \beta y\right]$. First assume $p_{B}=\min \left[\frac{\beta+t+1}{2}, \beta y\right]=\beta y$. Under this assumption, equilibrium profits are as presented in (22). Differentiating with respect to $t$ and rearranging, we find that $\frac{\partial \pi_{A}}{\partial t}+\frac{\partial \pi_{B}}{\partial t}>0 \Leftrightarrow \beta-t<2 \beta^{2} y$. Because $\beta y>\frac{\beta+1}{2}$ by assumption, the latter is satisfied for any $t$. Next assume instead that $p_{B}=\min \left[\frac{\beta+t+1}{2}, \beta y\right]=\frac{\beta+t+1}{2}$. Replacing this expression in (16) - (18), and making use of (2) and (3), we can write profit of downtown stores A and of the suburban store B as, respectively:

$$
\pi_{A}=\frac{1}{2}\left(\frac{3 \beta-t+1}{2(2 \beta+1)}\right)^{2}, \quad \pi_{B}=\frac{(\beta+t+1)^{2}}{4(2 \beta+1)} .
$$

Differentiating with respect to $t$ and rearranging, we find that $\frac{\partial \pi_{A}}{\partial t}+\frac{\partial \pi_{B}}{\partial t}>0 \Leftrightarrow 2(\beta+t+1)(2 \beta+1)>3 \beta-t+1$. Working out, it immediately follows that this expression is again satisfied for any $t$. We can conclude, therefore, that if $t^{e}$ is an interior solution (i.e., (A2.1) is equal to zero), then it must be the case that $t^{e}>t^{*}$. Finally, note that if $t^{e}$ is a corner solution, it cannot be such that $t^{e}=0$. Indeed, both $\frac{\partial S W}{\partial t}$ and $\frac{\partial \pi_{A}}{\partial t}+\frac{\partial \pi_{B}}{\partial t}$ are strictly positive when evaluated at $t=0$, implying that $\frac{\partial W_{G}}{\partial t}>0$. We have therefore shown that $\beta y>\frac{\beta+1}{2}$ necessarily yields $t^{e}>t^{*}$.

\section{Appendix 3: Heterogeneous goods}

In this appendix, we briefly analyze the case of heterogeneous goods considered in Section 4. We first derive equilibrium demands, prices and profits, next we study the social optimum. Finally, we provide conditions that ensure the market equilibrium entails multiple-stop shopping.

\section{Derivation of the socially optimal allocation}

Using the fact that $q_{d}=\overline{\bar{x}}, q_{A, \mathrm{f}}=\bar{x}$ and $q_{B, \mathrm{f}}=q_{B, \mathrm{~s}}=1-\bar{x}$, the social welfare function can be written as: 


$$
\begin{aligned}
& S W=\int_{0}^{\bar{x}} U(x ; A) d x+\int_{\bar{x}}^{\overline{\bar{x}}} U(x, A B) d x+\int_{\overline{\bar{x}}}^{1} U(x ; B) d x+\sum_{i=A, B} \pi_{i}-e \overline{\bar{x}}+t \overline{\bar{x}}= \\
& =V_{d} \overline{\bar{x}}+V_{s}(1-\bar{x})+V_{f}-\beta \frac{\bar{x}^{2}}{2}-\beta(1-\bar{x})+\beta\left(\frac{1-\overline{\bar{x}}^{2}}{2}\right)-\frac{\bar{x}^{2}}{2}-\frac{\overline{\bar{x}}^{2}}{2}-e \overline{\bar{x}} .
\end{aligned}
$$

Maximizing social welfare with respect to $\bar{x}$ and $\overline{\bar{X}}$, assuming that $1>\overline{\bar{X}}>\bar{X} \geq 0$ in the socially optimal allocation, we get

$$
\overline{\bar{x}}=q_{d}=\frac{V_{d}-e}{\beta+1}, \bar{x}=q_{A, \mathrm{f}}=\max \left[0, \frac{\beta-V_{s}}{\beta+1}\right], 1-\bar{x}=q_{B, \mathrm{f}}=q_{B, \mathrm{~s}}=\min \left[\frac{1+V_{s}}{\beta+1}, 1\right] .
$$

Because we assume that $1>\overline{\bar{X}}>\bar{x} \geq 0$ in the optimal allocation, the following condition has to hold

$$
\beta+1+e>V_{d}>e+\max \left[0, \beta-V_{s}\right] .
$$

Equilibrium demands, prices and profits

The various demands can be written as

$$
\begin{aligned}
& q_{d}=\overline{\bar{x}}=\min \left[\frac{V_{d}-p_{d}-t}{\beta}, 1\right], \\
& q_{\mathrm{A}, \mathrm{f}}=\bar{x}=\max \left[0, \frac{\beta+p_{B, \mathrm{f}}-p_{A, \mathrm{f}}-\left(V_{s}-p_{B, \mathrm{~s}}\right)}{\beta}\right], \\
& q_{B, \mathrm{f}}=q_{B, \mathrm{~s}}=1-\bar{x}=\min \left[\frac{\left(V_{s}-p_{B, \mathrm{~s}}\right)+p_{A, \mathrm{f}}-p_{B, \mathrm{f}}}{\beta}, 1\right] .
\end{aligned}
$$

Since downtown retailers are price-taking firms, in equilibrium we further have

$$
p_{A, k}=q_{A, k}, \quad k=d, \mathrm{f} .
$$

Hence, we can rewrite the quantities in (A3.2) as

$$
\begin{aligned}
& q_{d}=\overline{\bar{x}}=\min \left[\frac{V_{d}-t}{\beta+1}, 1\right], \\
& q_{A, \mathrm{f}}=\bar{x}=\max \left[0, \frac{\beta+p_{B, \mathrm{f}}-\left(V_{s}-p_{B, \mathrm{~s}}\right)}{\beta+1}\right], \\
& q_{B, \mathrm{f}}=q_{B, \mathrm{~s}}=1-\bar{x}=\min \left[\frac{1+V_{s}-p_{B, \mathrm{~s}}-p_{B, \mathrm{f}}}{\beta+1}, 1\right] .
\end{aligned}
$$

As in the baseline model, profit-maximization by store B implies:

$$
p_{B, \mathrm{~s}}+p_{B, \mathrm{f}}=\min \left[\beta y, \frac{1+V_{s}}{2}\right]
$$

where $p_{B, \mathrm{~s}}+p_{B, \mathrm{f}}=\frac{1+V_{s}}{2}$ maximizes B's profit in the absence of competition from C. This profit 
amounts to $\left(p_{B, \mathrm{~s}}+p_{B, \mathrm{f}}\right) \cdot \min \left[\frac{1+V_{s}-p_{B, \mathrm{~s}}-p_{B, \mathrm{f}}}{\beta+1}, 1\right]$. As in the baseline model (see (19) and the comments given there), we assume without loss of generality that

$$
\min \left[\beta y, \frac{1+V_{s}}{2}\right]=\beta y \Rightarrow p_{B, \mathrm{~s}}+p_{B, \mathrm{f}}=\beta y .
$$

Using this in (A3.5) we obtain the equilibrium quantities (conditional on the parking fee $t$ ) as described in (35). Note that quantities in (35) are presented under the implicit assumption that $\bar{X}>0$ and $\overline{\bar{x}}<1$. Replacing $q_{A, \mathrm{f}}$ and $q_{d}$ in (A3.4) and using (A3.6), we obtain (36). Finally, to obtain (37) , one needs to replace these equilibrium quantities and prices in (2) and (3).

\section{The socially optimal parking fee}

Comparing (A3.1) with the equilibrium quantities in (35), and noting that equilibrium quantities $q_{A, \mathrm{f}}, q_{B, \mathrm{f}}$, and $q_{B, \mathrm{~s}}$ are unaffected by $t$, we get that the optimal parking fee is $t^{*}=e$.

\section{Conditions for existence of the market equilibrium with multiple-stop shopping}

We now describe the conditions that have to be satisfied for the market equilibrium (conditional on $t$ ) to be consistent with our assumptions.

We assume that $p_{B, \mathrm{f}} \leq p_{A, \mathrm{f}}$ and $p_{B, \mathrm{~s}} \leq V_{s}$. By (A3.4), (A3.5) and (A3.6), these inequalities are satisfied if $p_{B, \mathrm{f}} \leq \max \left[0, \frac{\beta+\beta y-V_{s}}{\beta+1}\right]$, and $p_{B, \mathrm{~s}} \leq V_{s}$. We assume these conditions are satisfied. However, for consistency, $\beta y$ cannot exceed the sum $\frac{\beta+\beta y-V_{s}}{\beta+1}+V_{s}$, which requires that $V_{s}+1 \geq \beta y$. We assume this inequality holds.

Furthermore, we assumed that $1 \geq \overline{\bar{x}}>\bar{x} \geq 0$. In order to outline the conditions that have to hold for the market equilibrium to be consistent with this assumption, we proceed by considering the case where $\bar{x}>0$ and $\bar{x}=0$ separately. Consider first the case where $\bar{X}>0$. The market equilibrium is then as described in (35) - (37). Given (35), $\bar{x}>0$ if and only if $\beta+\beta y>V_{s}$. We have

$$
\overline{\bar{x}}>\bar{x} \Leftrightarrow t<V_{d}+V_{s}-\beta-\beta y .
$$

Because $t \in[0, \beta+\beta y]$, condition

$$
2(\beta+\beta y)-V_{s}<V_{d}
$$

is sufficient for $\overline{\bar{X}}>\bar{x}$ to hold.

Consider now the case where $\bar{x}=0$. In words, all consumers shop in the suburbs, but some 
also buy good $d$ downtown. Replacing $p_{B, \mathrm{~s}}+p_{B, \mathrm{f}}$ from (A3.6) in (A3.5), we have that $\bar{x}=0$ if and only if $\beta+\beta y \leq V_{s}$. Furthermore, given (A3.5), condition $t<V_{d}$ has to hold for $\overline{\bar{X}}>\bar{x}=0$. Because $t \in[0, \beta+\beta y]$, condition

$$
\beta+\beta y<V_{d}
$$

is sufficient for $\overline{\bar{x}}>\bar{x}$ to hold. Summing up, when $\beta+\beta y<\min \left[V_{s}, V_{d}\right]$, the market equilibrium is such that $\overline{\bar{x}}>\bar{x}=0$. From (A3.5), we have $q_{d}=\min \left[\frac{V_{d}-t}{\beta+1}, 1\right], q_{A, \mathrm{f}}=0$ and $q_{B, \mathrm{f}}=q_{B, \mathrm{~s}}=1$. Because demand for B is independent of $t$, the result in Proposition 2 does not change.

\section{Appendix 4: Lobbying by residents: proof of some intermediate results}

To arrive at (45), we use (40), the fact that $N_{A}=\bar{\theta}$ and $p_{A}=\frac{Q_{A}}{N_{A}}$ to obtain that $\frac{1}{2}\left(\frac{Q_{A}}{N_{A}}\right)^{2}=N_{A}$ . This expression implicitly defines $N_{A}$. Applying the implicit function theorem, we get (45).

To arrive at (46), we start from individual profit in (44). Integrating over $c$ and recalling that $N_{A}=\bar{\theta}$, we have

$$
\int_{0}^{N_{A}} \pi_{A}\left(N_{A}, \theta\right) d \theta=N_{A} \frac{1}{2}\left(\frac{Q_{A}}{N_{A}}\right)^{2}-\frac{N_{A}^{2}}{2}
$$

Using $\frac{1}{2}\left(\frac{Q_{A}}{N_{A}}\right)^{2}=N_{A}$, we have $\int_{0}^{N_{A}} \pi_{A}\left(N_{A}, \theta\right) d \theta=\frac{N_{A}^{2}}{2}$. Differentiating, we have (46).

To arrive at (49), start by differentiating welfare in (41) with respect to $t$. We get

$$
\frac{d S W}{d t}=\frac{d Q_{A}}{d t}\left[\beta-e-v N_{R}-\frac{Q_{A}}{N_{A}}\left(2 \beta N_{A}+1\right)\right]+v N_{R} \frac{\partial N_{A}}{\partial t}+\left(\frac{1}{2}\left(\frac{Q_{A}}{N_{A}}\right)^{2}-N_{A}\right) \frac{\partial N_{A}}{\partial t} .
$$

Noting that $\frac{1}{2}\left(\frac{Q_{A}}{N_{A}}\right)^{2}=N_{A}$ as shown above, and using the formula for $Q_{A}$ in (42), (A4.1) boils down to

$$
\frac{d S W}{d t}=\frac{d Q_{A}}{d t}\left[t-e-v N_{R}\right]+v N_{R} \frac{\partial N_{A}}{\partial t} .
$$

Expression (49) follows from the fact the optimal fee satisfies $\frac{d S W}{d t}=0$. 